Research Article

\title{
Cascade Control of Grid-Connected PV Systems Using TLBO-Based Fractional-Order PID
}

\author{
Afef Badis ${ }^{\mathbb{D}},{ }^{1}$ Mohamed Nejib Mansouri, ${ }^{1}$ and Mohamed Habib Boujmil ${ }^{2}$ \\ ${ }^{1}$ Electronics and Microelectronics Laboratory (E $\mu$ E), The National Engineering School of Monastir (ENIM), \\ University of Monastir, Tunisia \\ ${ }^{2}$ Higher Institute of Technological Studies of Nabeul, Nabeul, Tunisia
}

Correspondence should be addressed to Afef Badis; badis.afef@gmail.com

Received 4 December 2018; Revised 20 February 2019; Accepted 13 March 2019; Published 16 May 2019

Academic Editor: Huiqing Wen

Copyright (c) 2019 Afef Badis et al. This is an open access article distributed under the Creative Commons Attribution License, which permits unrestricted use, distribution, and reproduction in any medium, provided the original work is properly cited.

Cascade control is one of the most efficient systems for improving the performance of the conventional single-loop control, especially in the case of disturbances. Usually, controller parameters in the inner and the outer loops are identified in a strict sequence. This paper presents a novel cascade control strategy for grid-connected photovoltaic (PV) systems based on fractional-order PID (FOPID). Here, simultaneous tuning of the inner and the outer loop controllers is proposed. Teachinglearning-based optimization (TLBO) algorithm is employed to optimize the parameters of the FOPID controller. The superiority of the proposed TLBO-based FOPID controller has been demonstrated by comparing the results with recently published optimization techniques such as genetic algorithm (GA), particle swarm optimization (PSO), and ant colony optimization (ACO). Simulations are conducted using MATLAB/Simulink software under different operating conditions for the purpose of verifying the effectiveness of the proposed control strategy. Results show that the performance of the proposed approach provides better dynamic responses and it outperforms the other control techniques.

\section{Introduction}

In recent years, solar energy has become one of the most potential renewable and environmentally friendly resources of energy thanks to its free gas emission, abundance, and low maintenance cost [1]. Usually, the solar energy is exploited either for stand-alone systems or for grid-connected photovoltaic $(\mathrm{PV})$ systems. Several papers in the literature are targeting the issue of grid-connected PV generator (PVG) [2], and studies are carried out in this issue in order to improve the overall efficiency of the system. In fact, the nonlinearity of the PV power systems and the unpredictable intrinsic and atmospheric changes, which make the operating point vary due to the control unit and the parametric errors, are the two key factors that should be thoroughly examined. Thus, the main objective in a grid-connected PV system is to ensure high performance with low cost by choosing the appropriate control strategy.
The control chain consists of two main parts, including the PVG-side control which ensures maximum extraction of PVG power using the appropriate MPPT algorithm and the grid-side control by controlling the DC bus voltage and injecting the desired power into the grid.

A considerable progress has been made over the last decade in optimization techniques. Among these methods, proportional-integral-derivative (PID) controllers are known to be the most widely used in many studies of grid-connected PV systems since they perform well in linear systems as compared to many new advanced control strategies, namely, model predictive control [3], neural control [4], and fuzzy PI control [5-7]. However, for nonlinear systems or with varying parameters, PID controllers become insufficient and unreliable, especially, when the performance requirements of the system are rigorous.

To overcome the weaknesses of the already cited control strategies, metaheuristic has recently emerged in the literature 
with new evolutionary techniques. Particle swarm optimization (PSO) was first developed in [8], and since then, it has gained much attention and become largely exploited in several fields [9-12]. PSO has the advantage of generating a high-quality solution within shorter calculation time and stable convergence characteristics in designing and tuning a PID controller [13]. Nowadays, teaching-learning-based optimization (TLBO) is a new optimization technique which outperforms the conventional methods. TLBO has been immersed in the literature for the purpose of tuning the PID parameters.

Moreover, performances of the classical PID controller can be further improved by setting the appropriate fractional-I and fractional-D actions. The fractional-order PID (FOPID) was firstly reported in [14] for a fractionalorder system. Since then, FOPID controllers concern more researchers to reach the most robust performance of various systems $[15,16]$.

Cascade control is one of the most commonly used complex control structures in industrial processes. It is implemented to enable faster disturbance rejection. Although sophisticated cascade control schemes have been proposed [17-19], the basic scheme still includes two nested loops with two controllers. Since this configuration requires the tuning of two controllers, cascade tuning systems are more complex than single-loop tuning systems. The usual approach is to first optimize the secondary regulator. The primary controller is then adjusted by evaluating the action of the secondary controller on the internal loop. Such a setting procedure takes a long time because at least two tests are usually necessary $[20,21]$. However, the sequential tuning procedure has been improved so that only one test is performed to adjust both controllers simultaneously [22].

Very limited studies are available in the literature for how to tune cascade control systems, and most of them change the original structure of the cascade control system. In [23], the authors have proposed a technique to tune the P/PI controllers and PID/PID simultaneously for the internal and external loop. It consists in finding the ideal parameters by the Maclaurin series. This method is compared with the method in $[24,25]$. The method in reference [23] outperforms the other methods.

In [26], GA is used to tune the P/PI and PID/PID controllers for the internal and external loops simultaneously. This method enables the user to select the performance criteria, which is not the case in [23]. GA has proven to be very effective in finding the optimal gains [27]. The GA-based method is compared to the method in [28]. Simulation results show the superiority of GA over the other methods.

Owing to the control design, this paper presents a comparative study of different metaheuristic-based control strategies to control the entire system which includes four cascaded controllers designed on the basis of the nonlinear system. On this topic, a TLBO-based FOPID controller is proposed to design a control strategy which is insensitive to parameter variations, perturbations, and nonlinearity and its parameters' gain is varying accordingly.

In the conventional cascade control, the controller parameters in the primary and secondary loops are tuned sequentially which makes the control more difficult and time-consuming. This paper describes a simultaneous tuning method for both GPV and grid-side cascade subsystems using the TLBO algorithm to estimate the appropriate parameters of the primary and secondary loop controllers. The control technique takes advantage of a simple but accurate control design technique.

The paper is organized as follows. Section 2 covers the PV system modeling. Section 3 encompasses the different control strategies. In section 4 , simulation results are discussed for various operating conditions. Comparison and comments supporting the performance and robustness of the TLBOFOPID control strategy are given. Finally, Section 5 draws the conclusion followed by References.

\section{Modeling of the Grid-Connected Photovoltaic System}

The PV interface configuration consists of two conversion stages. The first stage is made up of a PV generator and a DC-DC boost converter which executes the maximum power point tracking (MPPT) and follows the power reference while the second stage includes a three-phase inverter connected between the DC bus and the grid via a low-pass filter.

The Energetic Macroscopic Representation (EMR) for all components has been used for description and modeling of the PV conversion system as shown in Figure 1, while the Maximum Control Structure (MCS) allows modeling the control loops [29]. The EMR is interconnected in order to frame the EMR of the entire system. The used representation helps to understand the relations between all the system parameters and to design controllers for the system by characterizing the tuning chains. The MCS is generated by inversion of the EMR $[29,30]$.

In order to implement the control strategy, it is essential to provide control circuits either for the PVG voltage or for the currents injected into the grid, while maintaining the DC bus voltage, so as to obtain good module and phase accuracy and a rapid dynamic response.

The EMR model and its inverse MCS allow not only to decompose the system into two or more first-order subsystems but also to make its modeling systematic in view of its setting. Moreover, thanks to this decomposition, the system and its chain of control thus obtained lead to a structure consisting of nested loops which require a cascade control. This control provides good dynamic performance and is characterized by the following properties [31]:

(i) Cascading of two or more controllers of any type

(ii) Since the subsystems are of the first order, it is easier to stabilize the control circuits

(iii) The choice and dimensioning of the controller are facilitated. Conventionally, first is the control circuit of the inner loop in which the static converter control unit is treated, and then, the superposed control loop and so on are processed. In the current study, the two loops are tuned simultaneously. The block diagram of Figures 2 and 3 is obtained 


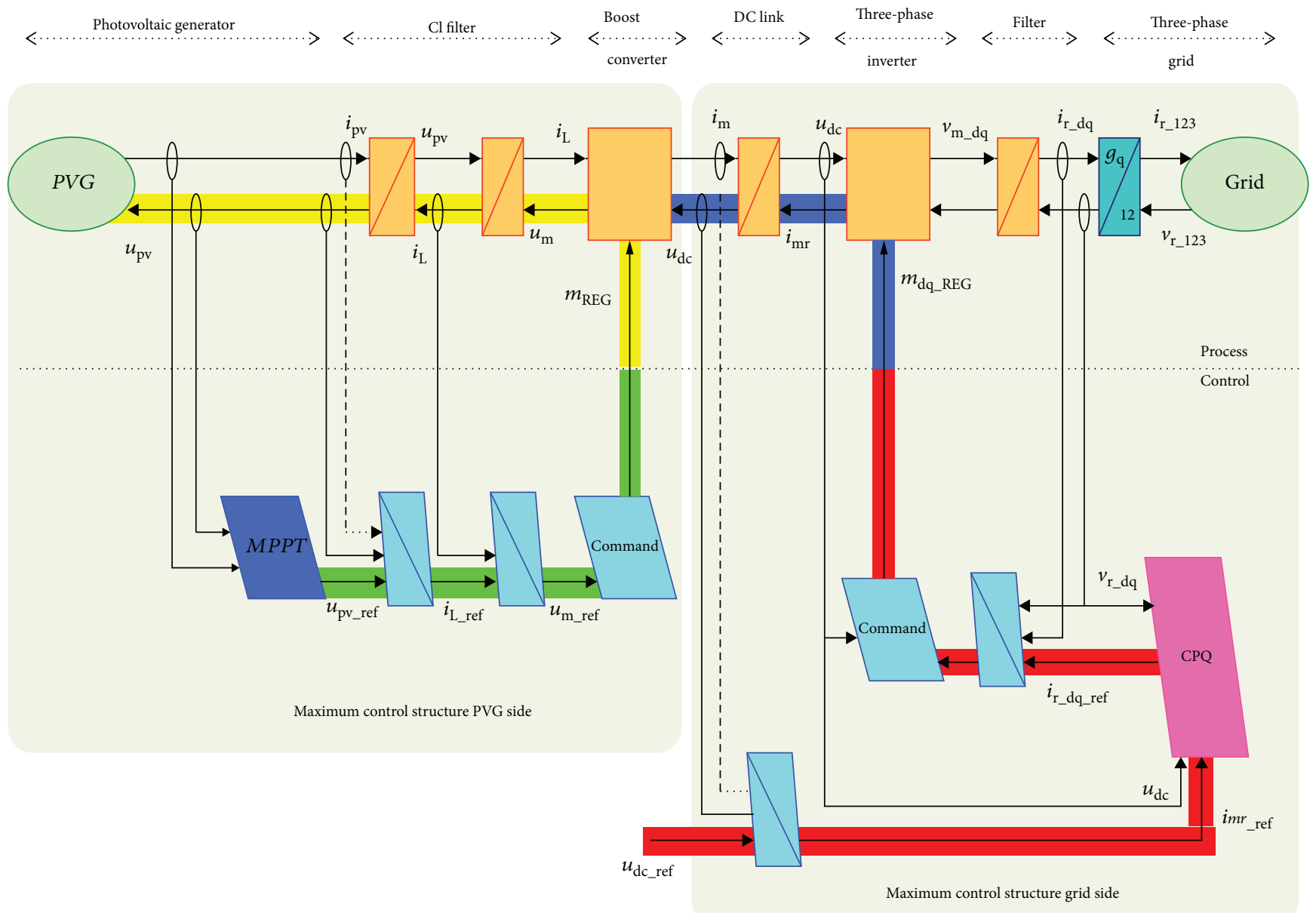

FIGURE 1: The EMR and its reverse MCS of the overall system.

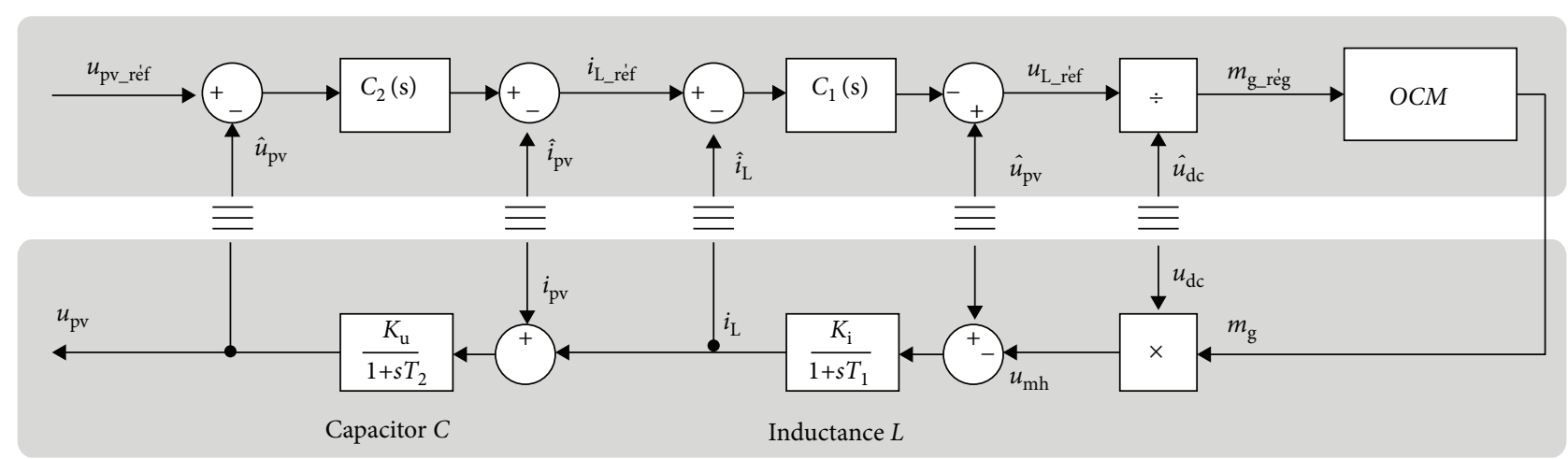

Figure 2: Block diagram of the PVG side.

\section{Presentation of the Proposed Control Strategy}

The main objective in a grid-connected PV system is to ensure high performances with low costs by choosing the adequate control strategy. Furthermore, the simplicity of the control algorithm is very crucial. This section deals with the presentation of the proposed control technique used for controlling the whole system. The control chain consists of two main subsystems including the PVG-side control which ensures the maximum power extraction from the PVG by using the appropriate MPPT and the grid-side control by controlling the DC link voltage and injecting the desired power to the grid.

3.1. Fractional-Order PID Controller. The FOPID controller presents a generic control loop feedback mechanism which attempts to reduce the error between a measured variable 


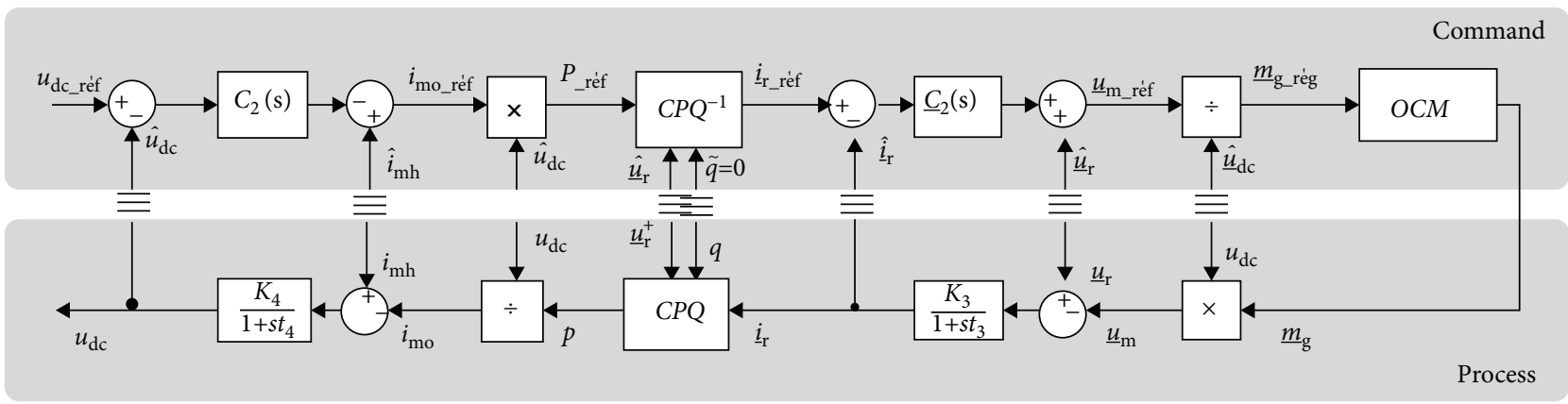

FIGURE 3: Block diagram of the grid side.

and the desired set point of a process. The generalized transfer function is given by

$$
C(s)=\frac{U(s)}{E(s)}=K_{P}+\frac{K_{I}}{s^{\lambda}} K_{D} s^{\mu} \quad(\lambda, \mu \geq 0)
$$

where $C(s)$ represents the controller output; $U(s)$ and $E(s)$ are the control signal and the error signal, respectively; $K_{P}$, $K_{I}$, and $K_{d}$ are the proportional, integral, and derivative constant gains, respectively; $\lambda$ is the order of integration; and $\mu$ is the order of differentiator [31].

If $\lambda=1$ and $\mu=1$, a classical PID controller is recovered. The FOPID controller generalizes the PID controller and expands it from point to plane by moving in the quarter plane defined by selecting the values of $\lambda$ and $\mu$ instead of jumping between four points. In general, researchers are using a range of 0 to 2 as the order of the FOPID.

3.2. TLBO-Based FOPID Tuning. This optimization technique was firstly invented by Rao et al. in 2011 [32]. Since then, TLBO has been rapidly emerged as a powerful optimization tool owing to the high-quality solutions and the good convergence it gives. It imitates the teaching and learning process between the teacher and learners in the class.

TLBO is based on a randomly generated population which consists of a class of students and it relies on two modes:

(i) Teacher mode where teachers learn students in a perfect way

(ii) Learners' mode where learning is made through interaction between learners

Initially, a matrix of $N$ rows and $D$ columns is randomly generated where $N$ represents the random initial population of initial solutions and $D$ is the dimension of each vector (number of subjects).

The $j^{\text {th }}$ parameter of the $i^{\text {th }}$ vector in the first generation is chosen randomly using the equation below:

$$
x_{(i, j)}^{1}=x_{j}^{\min }+\operatorname{rand}_{(i, j)}\left(x_{j}^{\max }-x_{j}^{\min }\right),
$$

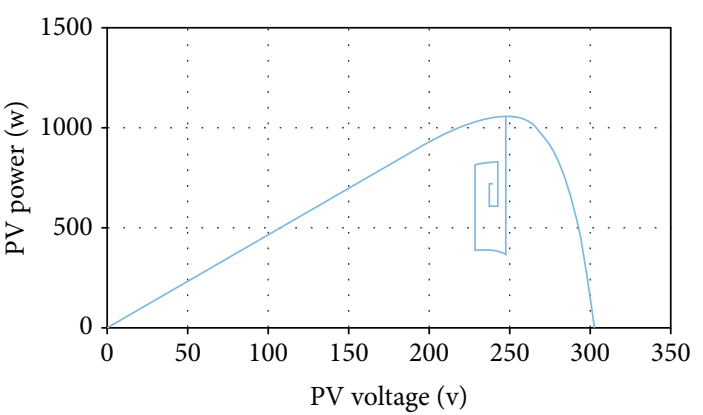

Figure 4: P-V curve with P\&O.

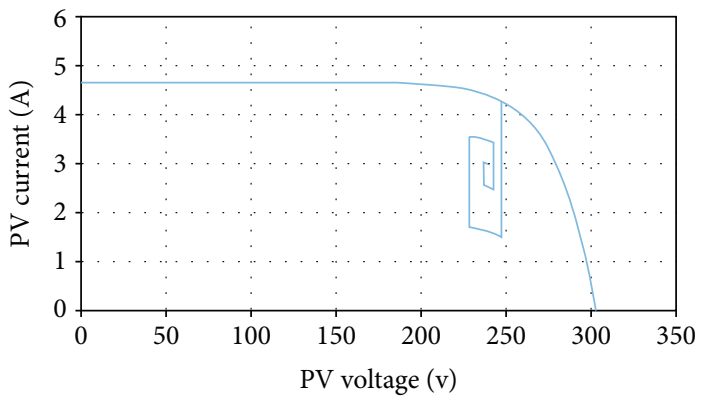

Figure 5: I-V curve with P\&O.

with $\operatorname{rand}_{(i, j)} \in[0.1]$.

The $i^{\text {th }}$ learner's vector for the $g^{\text {th }}$ generation can be expressed by

$$
X_{(i)}^{g}=\left[X_{(i, 1)}^{g}, X_{(i, 2)}^{g}, \ldots, X_{(i, j)}^{g}, \ldots, X_{(i, D)}^{g}\right]
$$

In the teacher mode, the student's result of an exam in a subject represents the fitness function to be optimized and the best learner becomes the teacher. The learners are motivated by the teacher and try to improve their own performance. Thus, the performance of each learner improves continuously through the process of information sharing between the teacher and learners. 


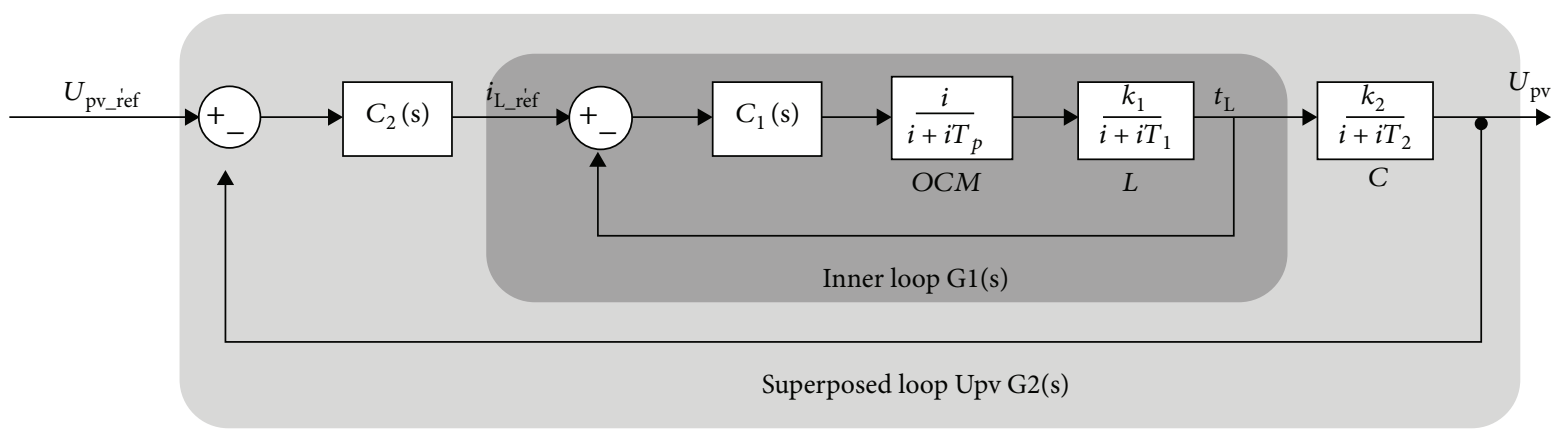

FIgURE 6: The simplified block diagram of the process.

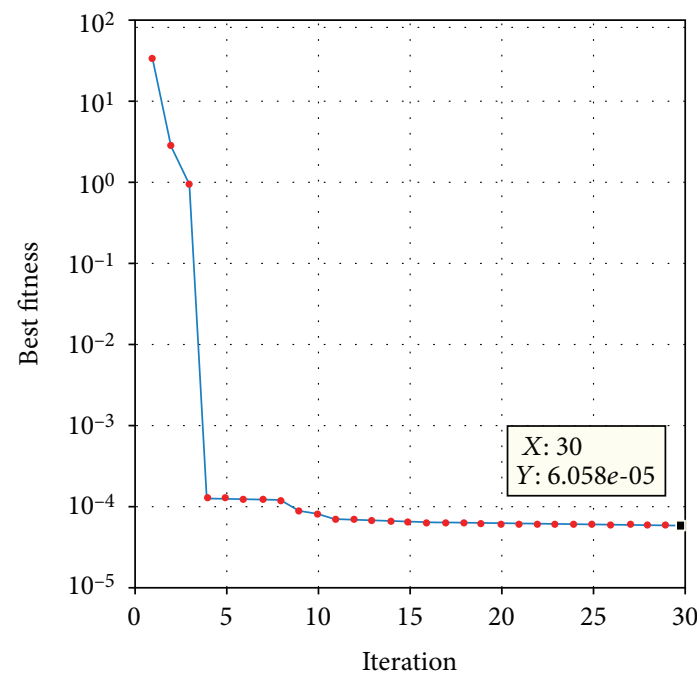

$\rightarrow$ Function fitness per TLBO

(a)

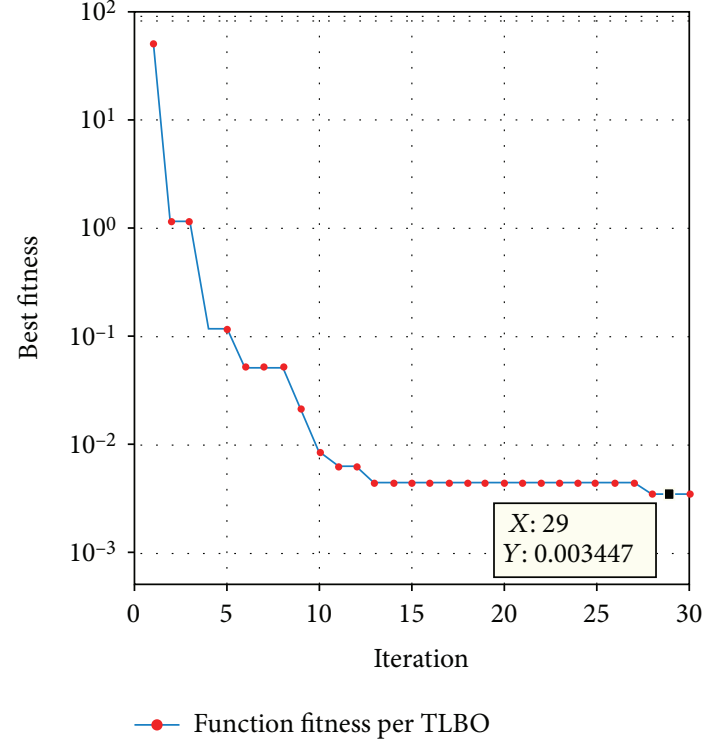

(b)

Figure 7: Convergence of the fitness function of the inner loop $i_{\mathrm{L}}(\mathrm{a})$ and the outer loop $U_{\mathrm{pv}}(\mathrm{b})$.

TABLE 1: Controller parameters of the $U_{\mathrm{pv}}$ loop.

\begin{tabular}{|c|c|c|c|c|c|}
\hline Parameters & $P$ & $I$ & $D$ & $\Lambda$ & $M$ \\
\hline PSO-PID & 0.3448 & 0.0869 & 0 & - & _- \\
\hline TLBO-FOPID & 1.45974 & 0.03948 & 0.00597 & 0.88048 & 0.46836 \\
\hline ACO-PID & 0.6232 & 2.3787 & 0 & _ & _ \\
\hline GA-FOPID & 0.2783 & 0.0095 & 0 & 1.1049 & 0.3005 \\
\hline
\end{tabular}

TABLE 2: Controller parameters of the $i_{\mathrm{L}}$ loop.

\begin{tabular}{|c|c|c|c|c|c|}
\hline Parameters & $P$ & $I$ & $D$ & $\Lambda$ & $M$ \\
\hline PSO-PID & 166.7585 & 617.1194 & 0 & _ & _ \\
\hline TLBO-FOPID & 22.40959 & 0.14503 & 0 & 0.10325 & 0 \\
\hline$A C O-P I D$ & 0.67797 & 0.89969 & 0.18383 & - & - \\
\hline GA-FOPID & 228.1800 & 18.7110 & 0 & 0.1768 & 0.4135 \\
\hline
\end{tabular}



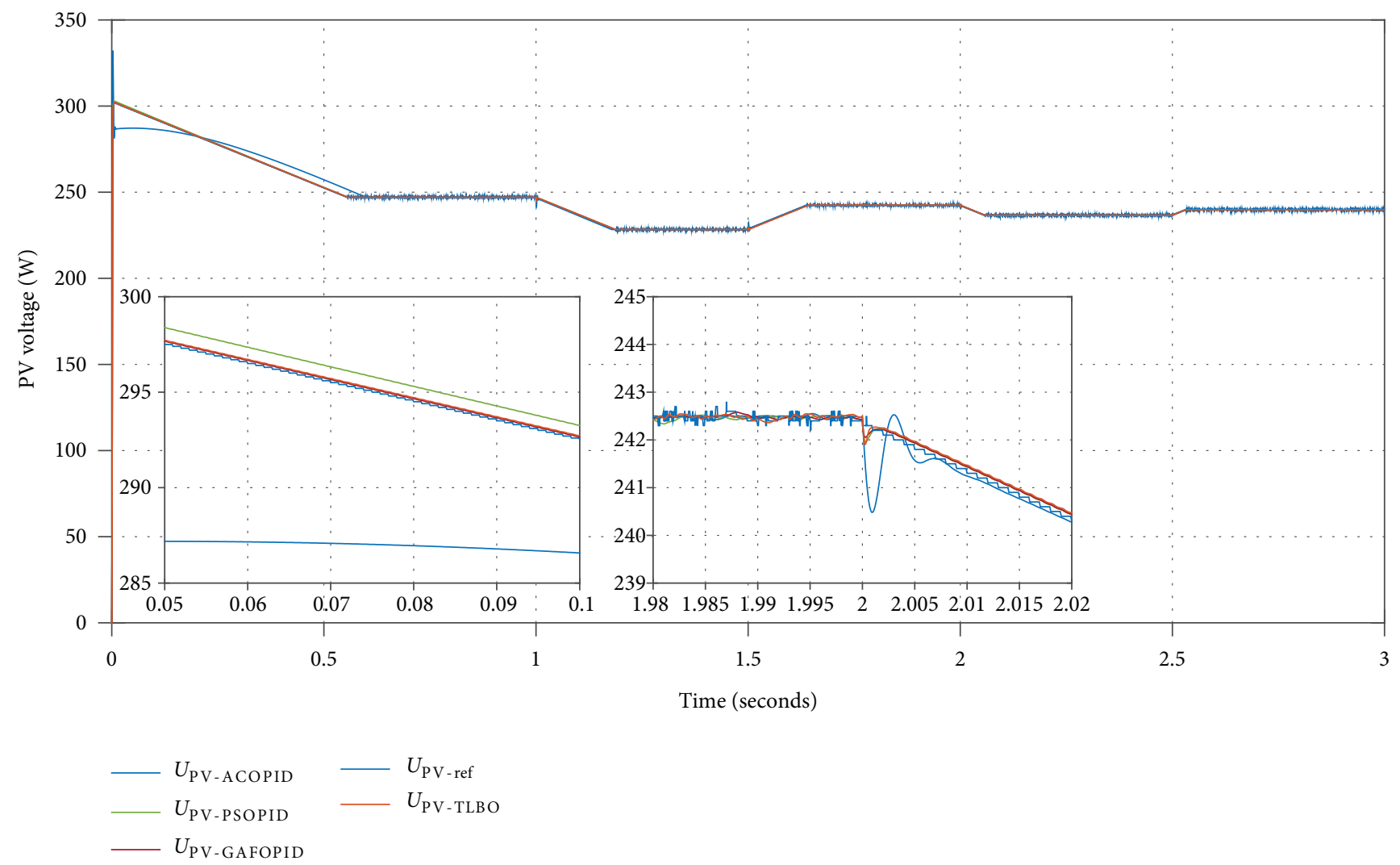

FIGURE 8: $U_{\mathrm{pv}}$ voltage at varying irradiation.

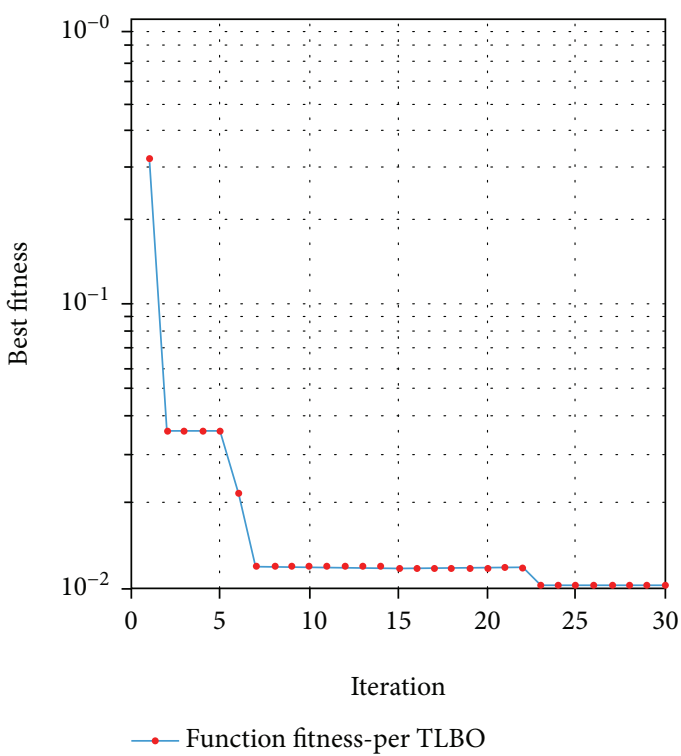

(a)

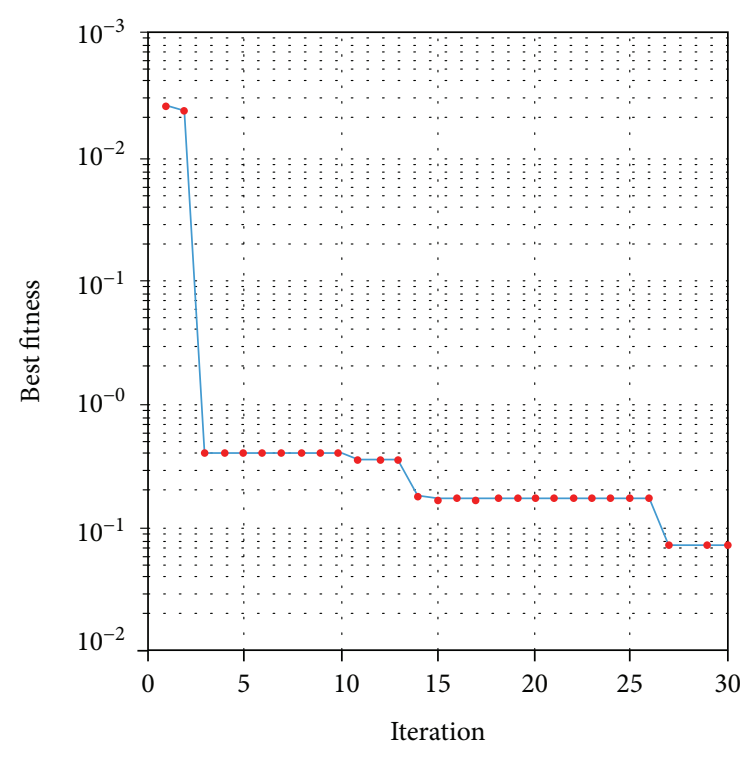

- Function fitness-per TLBO

(b)

FIGURE 9: Convergence of the fitness function of the inner loop $i_{\mathrm{dq}}$ (a) and the outer loop $U_{\mathrm{dc}}(\mathrm{b})$. 


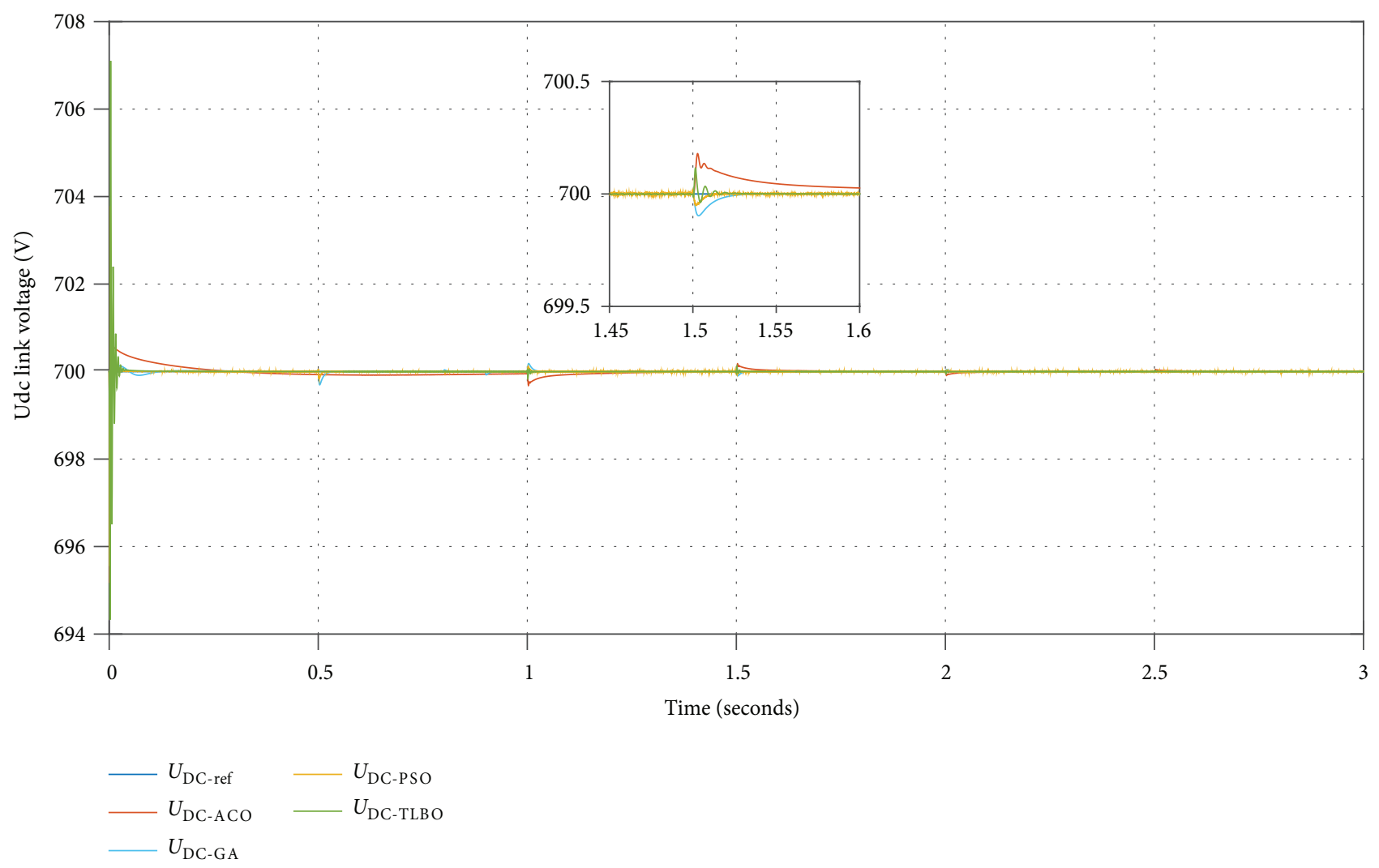

FIGURE 10: $U_{\mathrm{dc}}$ link voltage at varying irradiation.

TABLE 3: Controller parameters of the $U_{\mathrm{dc}}$ loop.

\begin{tabular}{lccccc}
\hline Parameters & $P$ & $I$ & $D$ & $\Lambda$ & \multicolumn{1}{c}{. } \\
\hline PSO-PID & 10 & 10 & 0 & 0.30639 & 0.044487 \\
TLBO-FOPID & 1.35201 & 1.08842 & 0.018702 & - \\
ACO-PID & 0.4633 & 0.5796 & 0 & - \\
GA-FOPID & 0.50140 & 0.0068 & 0 & 1.0748 & 0.08004 \\
\hline
\end{tabular}

TABLE 4: Controller parameters of $i_{\mathrm{dq}}$ loop.

\begin{tabular}{|c|c|c|c|c|c|}
\hline Parameters & $P$ & $I$ & $D$ & $\Lambda$ & $M$ \\
\hline PSO-PID & 156.4459 & 2.3633 & 0 & - & - \\
\hline TLBO-FOPID & 8.0678 & 37.2269 & 6.6273 & 0.3780 & 0.0879 \\
\hline$A C O-P I D$ & 0.0803 & 1.07 & 0.3727 & - & - \\
\hline GA-FOPID & 0.2783 & 0.0095 & 0 & 1.1049 & 0.3005 \\
\hline
\end{tabular}

The vector below contains the learners' mean in the class for each subject at the $g^{\text {th }}$ iteration. The teacher has always the best mean.

$$
\begin{aligned}
M^{g}= & {\left[\sum_{(i=1)}^{N}\left(\frac{x_{(i, 1)}^{g}}{N}\right)_{(i=1)}^{N} \sum_{(i=1)}^{N}\left(\frac{x_{(i, 2)}^{g}}{N}\right)_{(i=1)}^{N} \ldots \sum_{(i=1)}^{N}\left(\frac{x_{(i, j)}^{g}}{N}\right)_{(i=1)}^{N}\right.} \\
& \left.\ldots \sum_{(i=1)}^{N}\left(\frac{x_{(i, D)}^{g}}{N}\right)_{(i=1)}^{N}\right] .
\end{aligned}
$$

A randomly weighted differential vector is formed and added to the existing population of learners according to the actual mean and the desired mean vector in order to get a new set of improved learners.

$$
X_{\text {new }_{(i)}}{ }^{g}=X_{(i)}^{g}+\operatorname{rand}^{g}\left(X_{\text {teacher }}^{g}-T_{F} M^{g}\right),
$$

where $T_{F}$ is randomly selected at each iteration (1 or 2). Each teacher improves the mean result of the class in the subject in charge of. Bad learners of the population are replaced by the best learners found through this phase. 


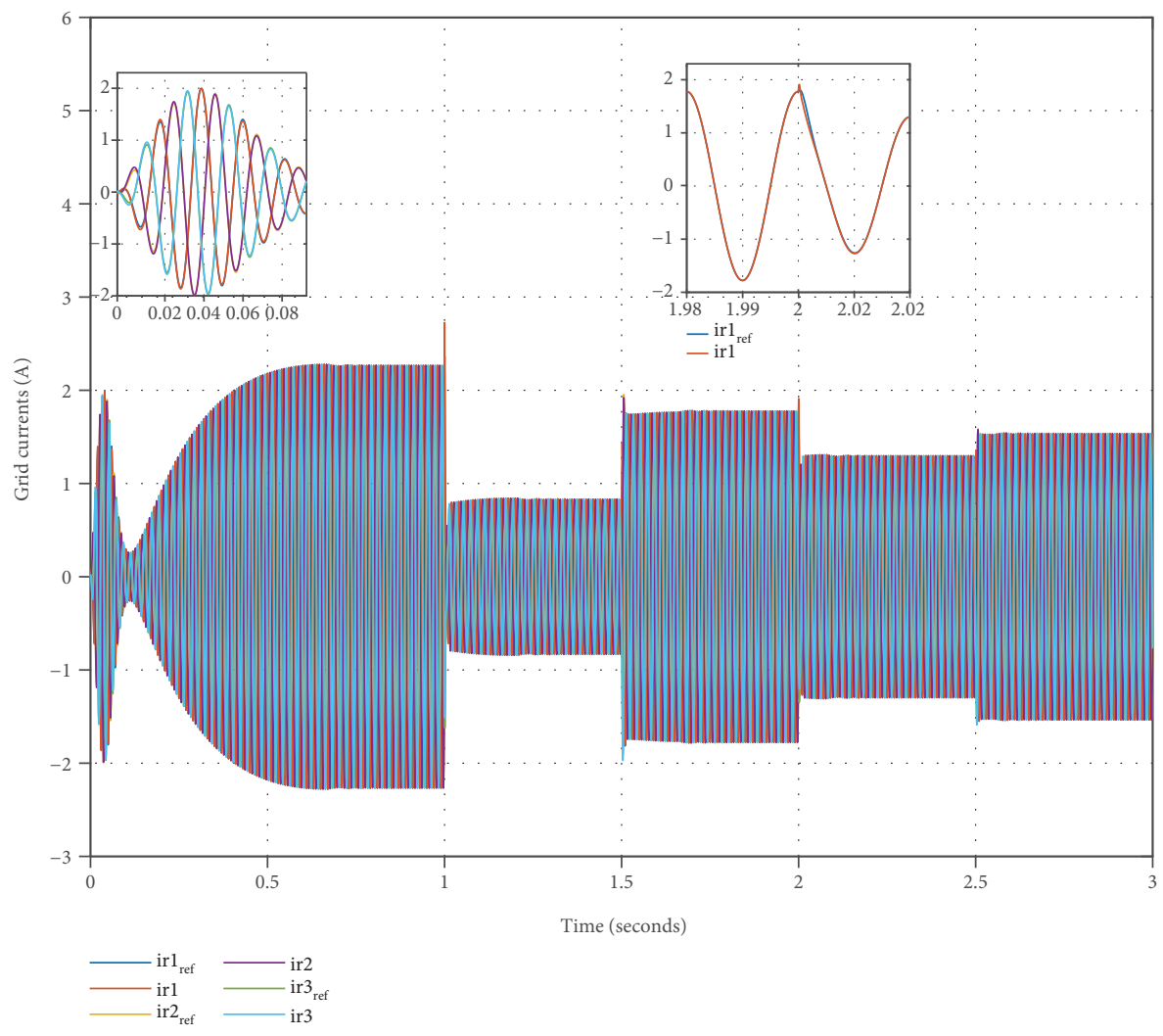

FIGURE 11: Grid currents (GA-FOPID control).

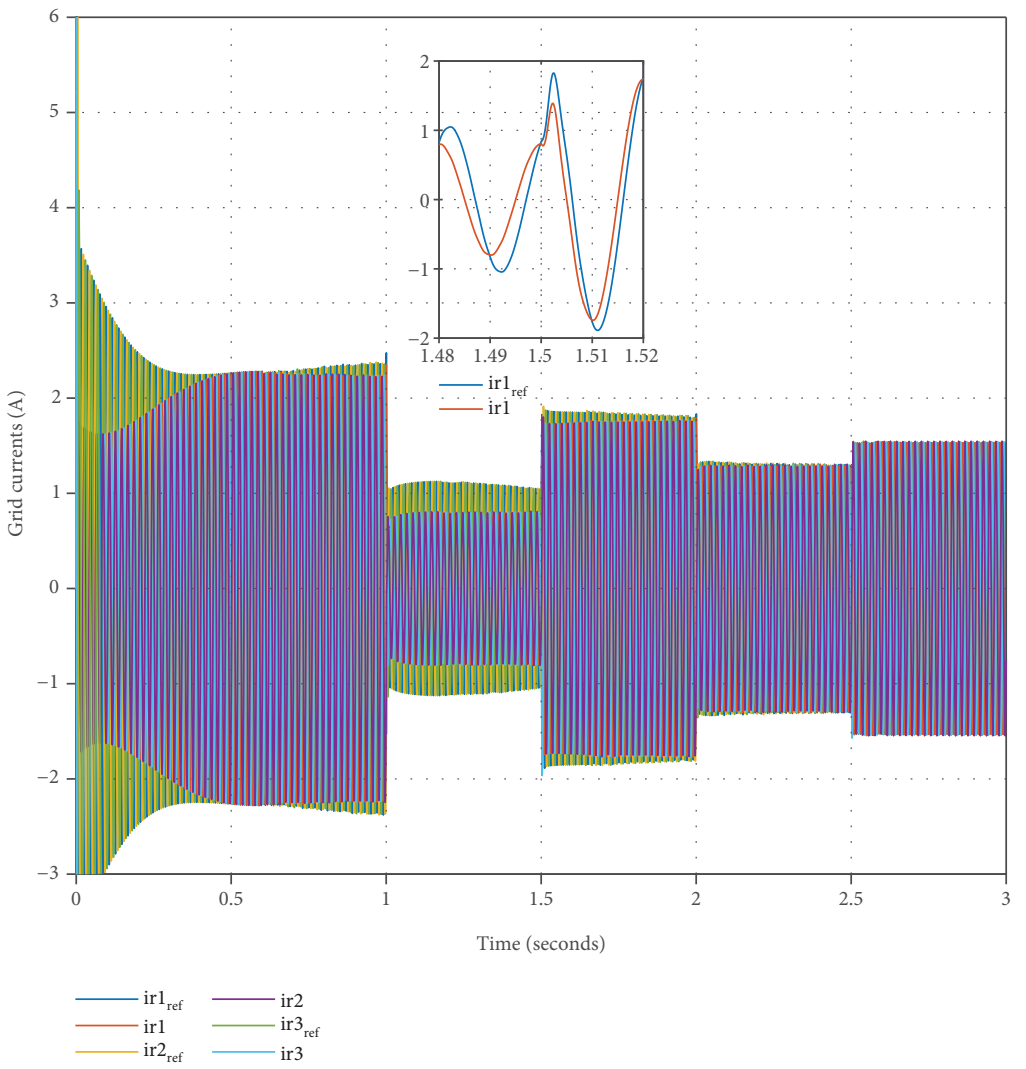

FIGURE 12: Grid currents (ACO-PID control). 


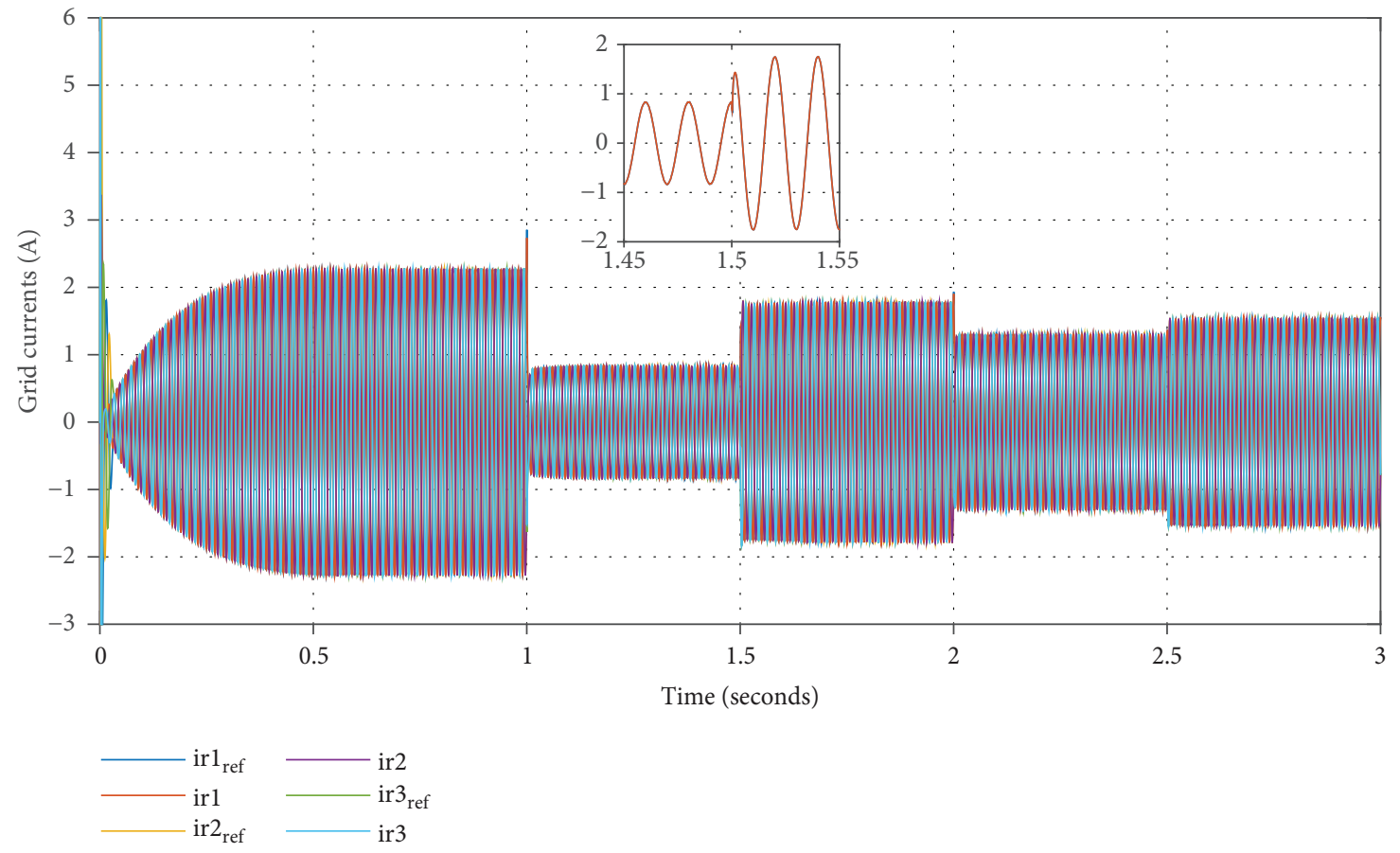

FIGURE 13: Grid currents (TLBO-FOPID).

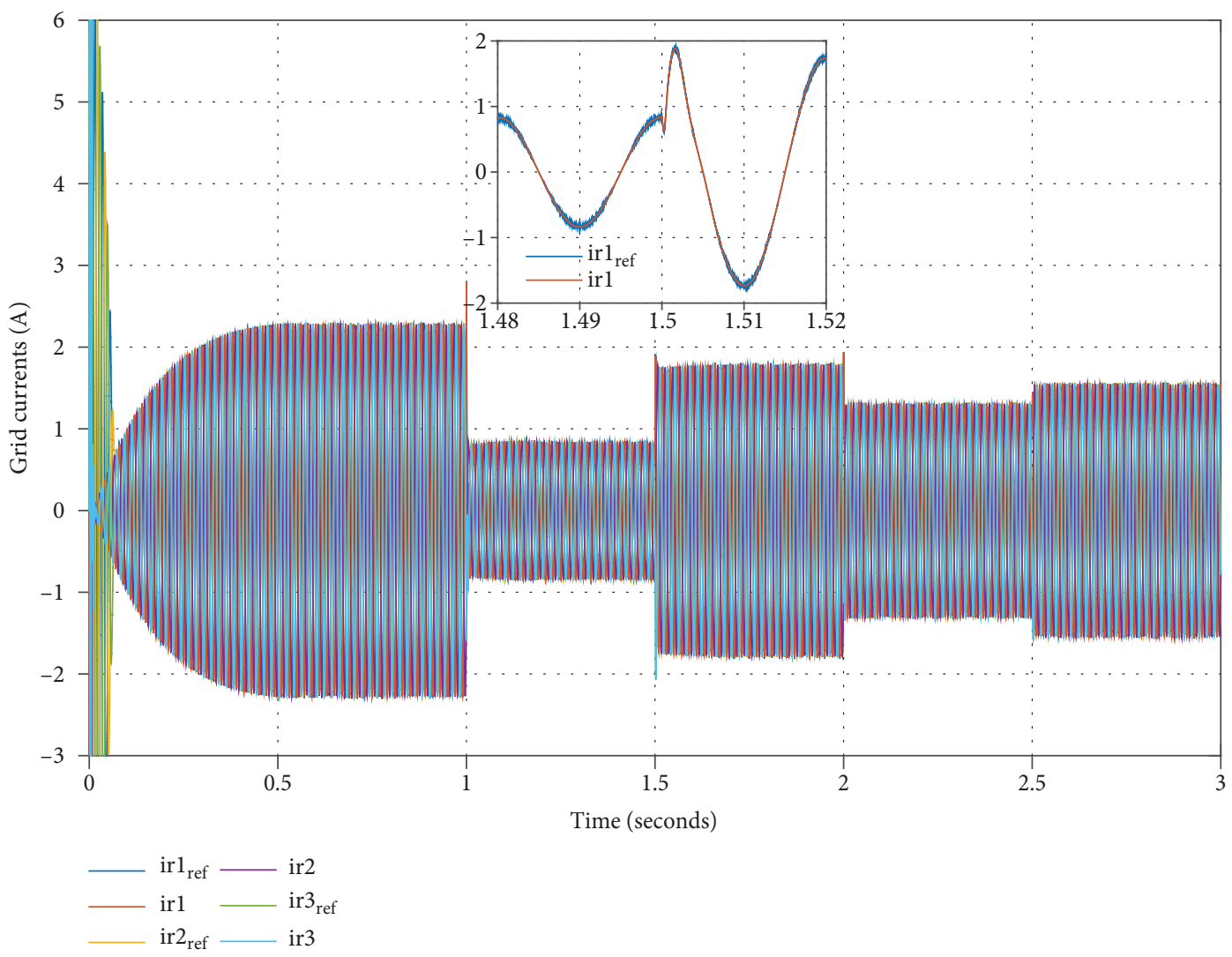

FIGURE 14: Grid currents (PSO-PID). 


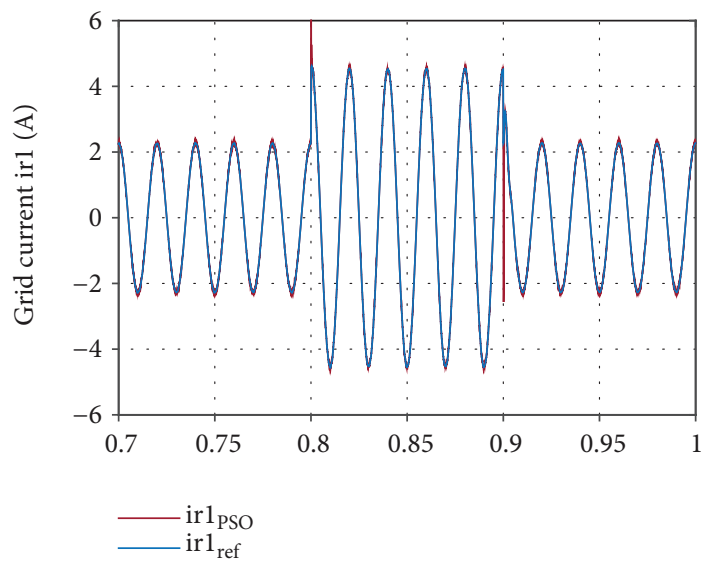

(a)

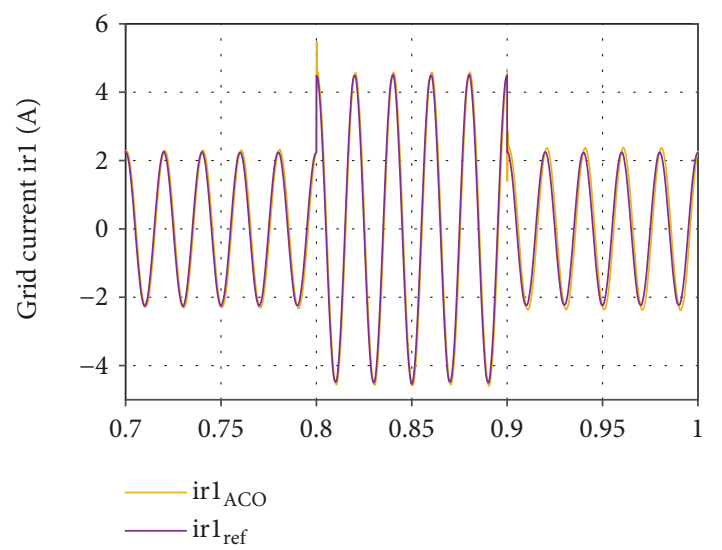

(c)

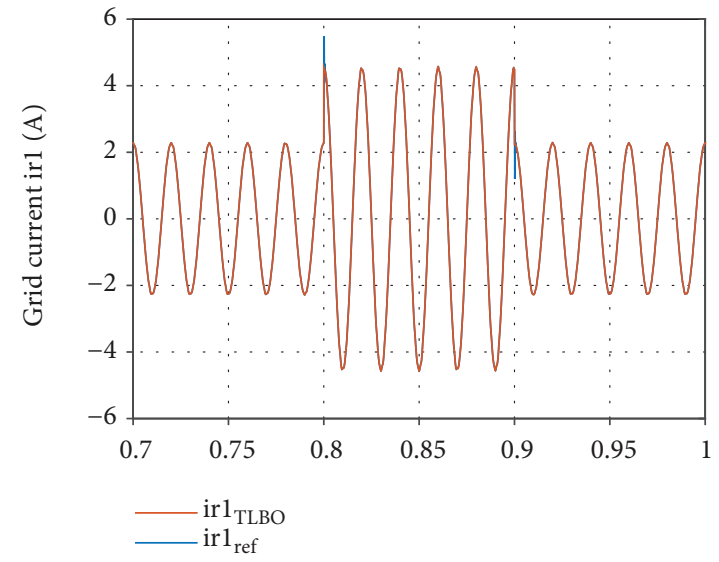

(b)

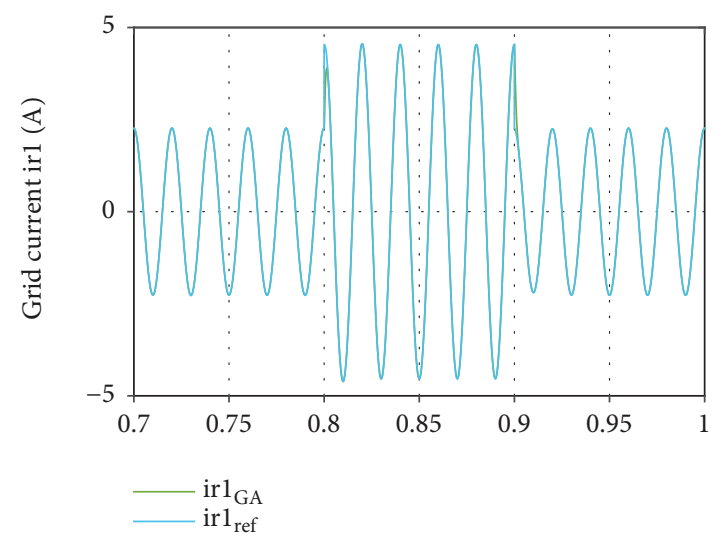

(d)

FIGURE 15: Voltage dip effect on grid currents without limitation by using (a) PSO-PID; (b) TLBO-FOPID; (c) ACO-PID; (d) GA-FOPID.

In the learner mode, learners interact with each other as well as with the teacher in order to boost their proficiency and facilitate the knowledge sharing.

This process of mutual interaction is randomly made. In fact, two learners $X_{(i)}^{g}$ and $X_{(r)}^{g}$ are randomly chosen $(i \neq r)$.

The $i^{\text {th }}$ vector of the $X_{\text {new }}$ matrix is given by

$$
X_{\text {new }_{(i)}} g=\left\{\begin{array}{l}
X_{(i)}^{g}+\operatorname{rand}_{(i)}^{g}\left(X_{i}^{(g)}-X_{(r)}^{g}\right) s i\left(Y_{i}^{g}<Y_{r}^{g}\right), \\
X_{(i)}^{g}+\operatorname{rand}_{(i)}^{g}\left(X_{(r)}^{g}-X_{(i)}^{g}\right) .
\end{array}\right.
$$

In this proposed work, the optimal values of the FOPID controllers' gains are obtained using the TLBO algorithm. The performance of many optimization techniques in the literature depends on the appropriate setting of certain control parameters. In the differential evolution algorithm, the control parameters are the scale factor and the crossing rate; in the PSO algorithm, the control parameters are the inertia weight $\omega$, social and cognitive parameters ( $c_{1}$ and $c_{2}$, respectively). The selection of these parameters is crucial to the performance of the algorithms. However, the TLBO algorithm does not require any control parameters. As it is a parameter-free algorithm, it is simple, efficient, and fast.

The proposed TLBO-based control ensures the optimum power transfer from the PV panel to the grid. In order to prove its reliability, the model of the whole system has been designed using MATLAB/Simulink software. The model has been then tested under different operating conditions. The control strategy is designed to tune the parameters $\left(K_{p}, K_{i}, K_{d}, \lambda\right.$, and $\left.\mu\right)$ of the FOPID/FOPID cascade controllers simultaneously in order to maintain the stability of the entire control system. The algorithm searches for the five controller parameters that most optimize the power transfer from the PVG to the grid. The optimization algorithm gradually and iteratively minimizes the integral performance index while finding the optimal set of parameters for FOPID/FOPID controllers following the steps described above. The algorithm ends if the value of the fitness function is kept constant appreciably over a few successive iterations.

3.3. Fitness Function. In order to prove the reliability of the proposed cascade control, it is implemented in the gridconnected PV system. Very limited researches which develop guidelines for tuning a FOPID controller are available. Reference [33] highlights the relationships between the order of differentiation $(\mu)$ and integration $(\lambda)$ and the time domain specifications. The existence of a particular relationship 


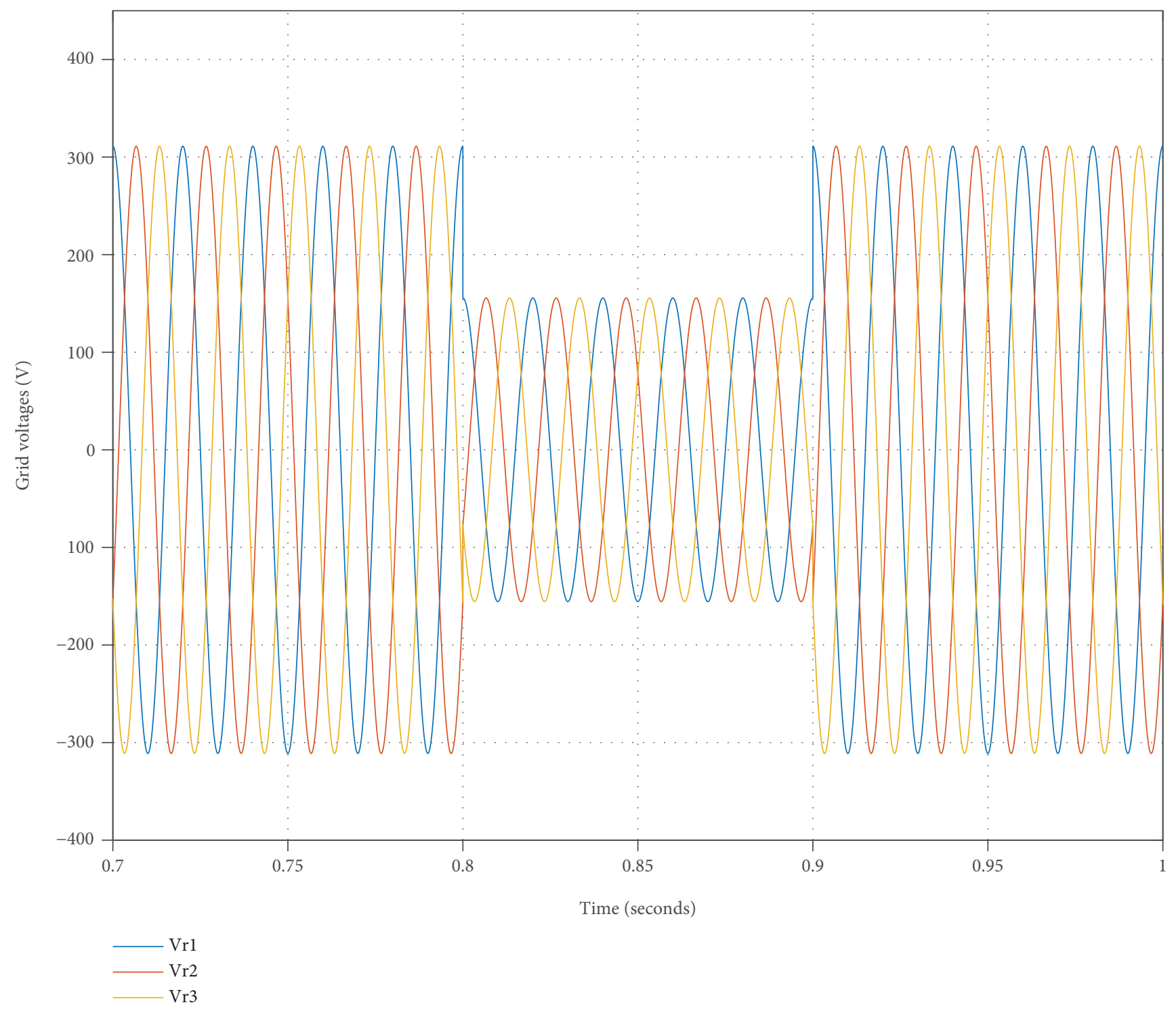

Figure 16: Voltage dip at $t=[0.8 \mathrm{~s}, 0.9 \mathrm{~s}]$.

between $\mu$ and the maximum overshoot has been proven. That is why the maximum overshoot is an important characteristic of a control system, and it is used as a measure of performance for optimization of the FOPID controller.

For each loop in the subsystem, controller performances are evaluated according the following fitness function as illustrated in equation (7) and equation (8).

$$
\begin{aligned}
\text { overshoot } & =\max \left(Y_{\text {out }}\right)-Y_{\text {ref }}, \\
F & =\alpha . \text { overshoot }+\beta . \text { ITAE } .
\end{aligned}
$$

As there is no preference between the two objectives, $\alpha=\beta=0.5$.

\section{Results and Discussion}

The instantaneous average model of the overall system is developed, and results of simulation of different strategies are carried out under the same conditions as follows:

$$
\begin{aligned}
P & =1 \mathrm{~kW}, \\
C & =220 \mu \mathrm{F}, \\
R & =100 \mathrm{k} \Omega, \\
L & =23 \mathrm{mH}, \\
C_{1} & =5000 \mu \mathrm{F}, \\
R_{1} & =10 k \Omega, \\
r_{1} & =0.0002 \Omega, \\
L_{1} & =1 \mathrm{mH}, \\
U_{r} & =380 \mathrm{~V}, \\
f & =50 \mathrm{~Hz} .
\end{aligned}
$$




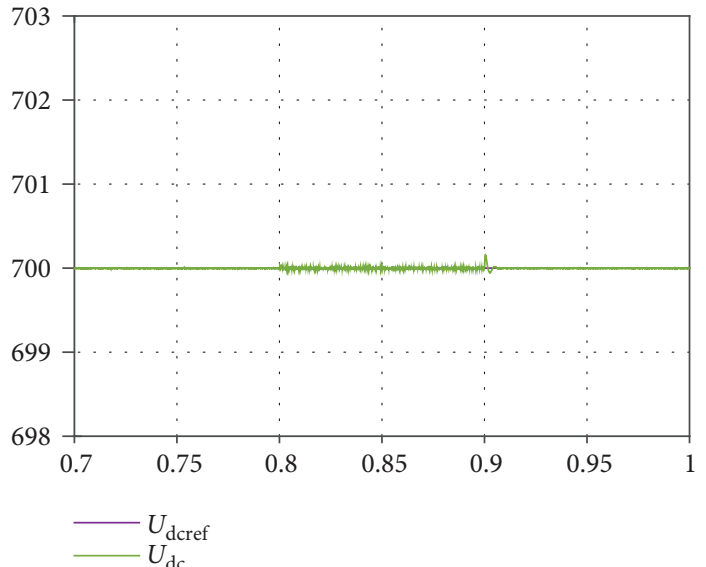

(a)

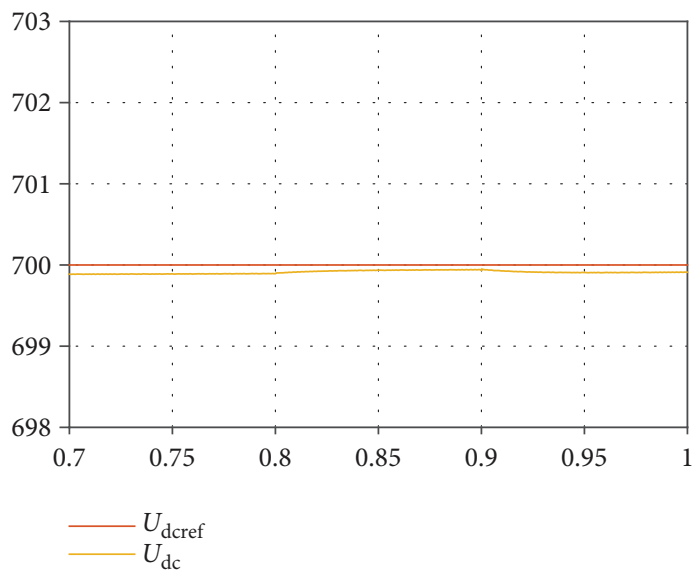

(c)

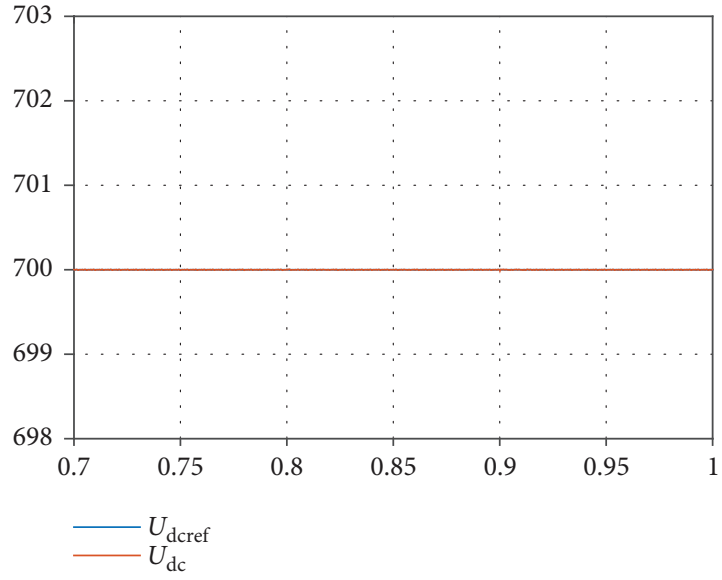

(b)

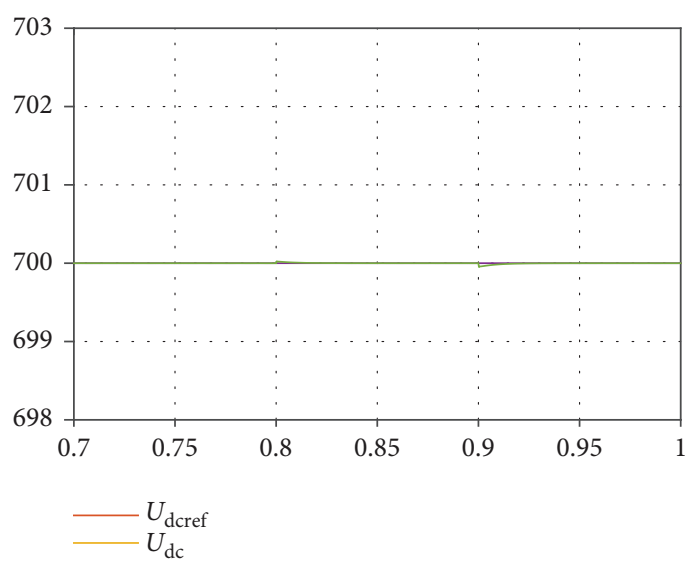

(d)

FIGURE 17: Voltage dip effect on DC link voltage without limitation by using (a) PSO-PID; (b) TLBO-FOPID; (c) ACO-PID; (d) GA-FOPID.

This section presents the control response of the proposed TLBO-based cascade control compared to PSO-PID, ACO-PID, and GA-FOPID for autotuning of the gains for each cascade control loop for sudden irradiation variations, sudden parametric variations, and under voltage dips of the grid.

4.1. Control under Sudden Irradiation Variations. Five irradiation step signals were simulated in order to evaluate the performance of the proposed algorithm. The ability of MPP tracking is demonstrated for the $\mathrm{P} \& \mathrm{O}$ method after every step change, and the maximum PV current and voltage are consequently extracted. Figures 4 and 5 show the good tracking results obtained in case of fast-changing conditions.

4.1.1. Stage 1: Cascade Control across the PVG. The simplified block diagram of the process and its control on the GPV side is shown in Figure 6. It shows that the $U_{\mathrm{pv}}$ voltage control of the PVG leads to a structure made up of two nested loops. As it can be seen, there are also two regulators $C_{1}(s)$ and $C_{2}(s)$ which, respectively, intervene on the current $i_{\mathrm{L}}$ and the voltage $U_{\mathrm{pv}}$. These two controllers are cascaded.

The $U_{\mathrm{pv}}$ voltage loop is the outer loop while the $i_{\mathrm{L}}$ current loop is an inner loop. The inner loop has been designed to have a relatively short response time in order to promptly correct the error. The outer loop can be configured to be slower.

First, the performance of the proposed algorithm is tested in each subsystem. The search for the parameters of the FOPID-FOPID controllers is carried out simultaneously, and the response corresponding to each set of gains is evaluated. The TLBO algorithm must gradually and iteratively minimize the integral performance index to find the optimal parameters for the FOPID-FOPID controllers of the inner and outer loop in order to find the best performance. The algorithm ends if the value of the fitness function is kept constant over a few successive iterations as shown in Figures 7(a) and 7(b) for the inner and outer loop, respectively, on the PVG side.

The TLBO algorithm is simulated with a small population size. This specification is important in order to allow a faster adjustment. In this study, the size of the initial populations is set at 20 for all control loops while the maximum number of iterations is set at 30 .

The gains of the controllers used for all loops on the GPV side are shown in Table 1. By providing better performance, FOPI controllers can be used instead of FOPID controllers, thanks to the reduced order of the inner loop subsystem. 


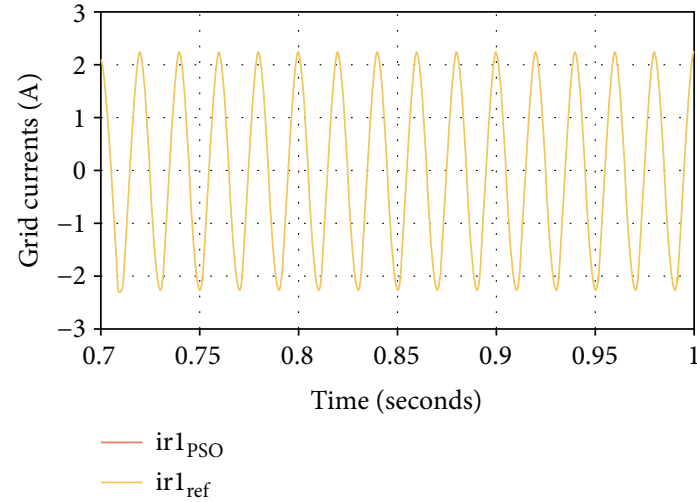

(a)

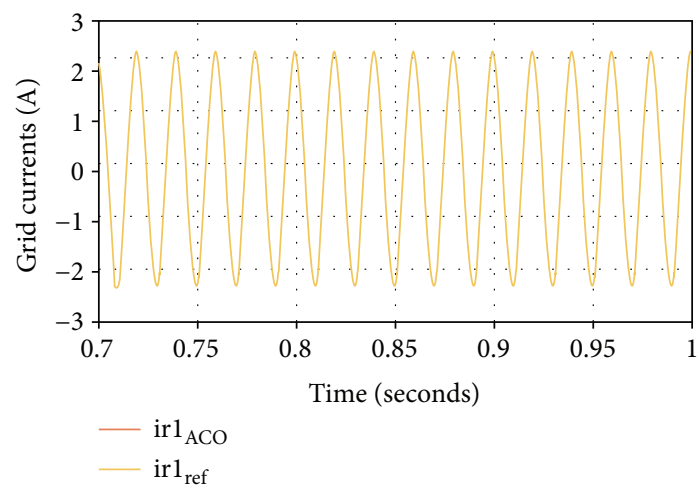

(c)

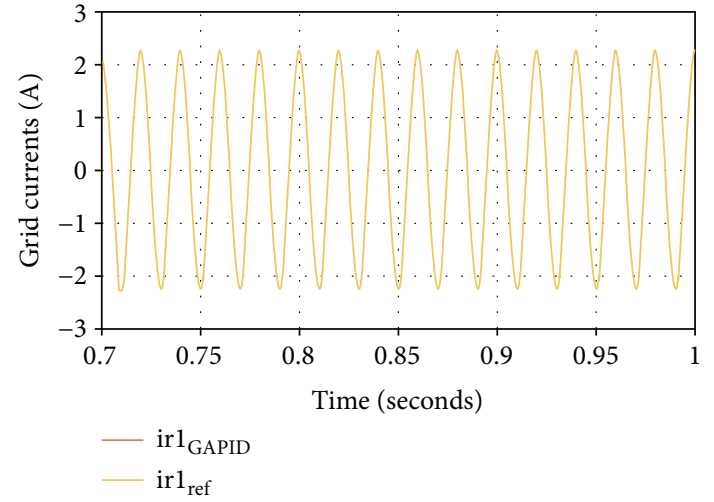

(b)

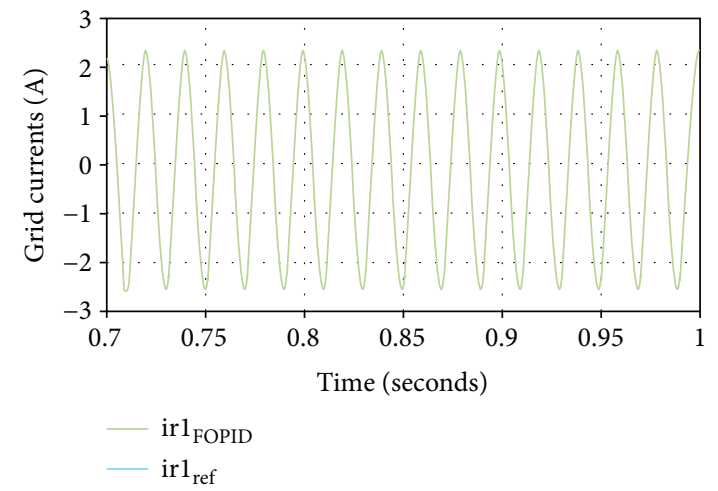

(d)

FIgURe 18: Voltage dip effect on grid currents with limitation by using (a) PSO-PID; (b) GA-FOPID; (c) ACO-PID; (d) TLBO-FOPID.

For the tuning of the $U_{\mathrm{pv}}$ loop, cascade control is obtained by controlling the two processes where the output of the inner process feeds the external process. The value of the fitness function reaches a minimal value after 28 iterations. The MPP search is performed simultaneously using the $\mathrm{P} \& \mathrm{O}$ algorithm. Controller gains of the current loop are shown in Table 2.

The simulation results are shown in Figure 8 for the PVG-side control. The results in the figure below show that the TLBO-based FOPID offers good performance for reference tracking. When the irradiation changes from one level to another, the FOPID-FOPID controller is able to quickly track the new power level for each subsystem.

ACO-PID is less reliable than the PSO-PID and GAFOPID. When the irradiation moves from one level to another, the TLBO-based FOPID tracks quickly the new power level. However, ACO-PID takes more time to find the steady state $\left(T_{\text {rise }}=0.5 \mathrm{~s}\right)$.

4.1.2. Stage 2 Grid-Side Control. The purpose of the control is to keep the DC bus voltage constant regardless of the power variation. The tuning of the $U_{\mathrm{dc}}$ outer loop by the TLBObased FOPID controller is completed after 30 iterations as shown in Figure 9. The value of the fitness function reaches a minimum value after 27 iterations (outer loop).

Figure 10 validates the DC bus controller which ensures a good monitoring of the DC voltage measured in relation to its reference. It can be seen that when the power increases, the DC voltage tries to increase simultaneously.

The FOPID controller very quickly reduces the error and always maintains the DC bus voltage at the same constant value $(700 \mathrm{~V})$.

Table 3 indicates the controller gains of the DC link voltage loop while Table 4 enumerates the controller gains of the grid current loop.

Figures 11-14 show the behavior of the grid current that is controlled in the inner loop with adequate control simultaneously with the DC bus voltage of the outer loop. The simulation is performed for a unity power factor under variable atmospheric conditions. No reactive power will be supplied to the grid since the voltage and current will be in phase with each other.

From Figure 13, it is clear that the TLBO cascade control is capable of generating the desired current. There is no phase difference between the grid voltage and the voltage for the designed controller. Indeed, the current loop regulator is validated and we can see that the measured current signals follow their references.

4.2. Control under Voltage Dips without Current Limitation. The target of the TLBO-FOPID control consists on keeping the DC link voltage stable independently of the power variation. Figure 15 highlights the impact of a grid voltage dip as depicted in Figure 16 for a constant irradiation $G=$ $1000 \mathrm{G} / \mathrm{m}^{2}$ on the grid currents. 


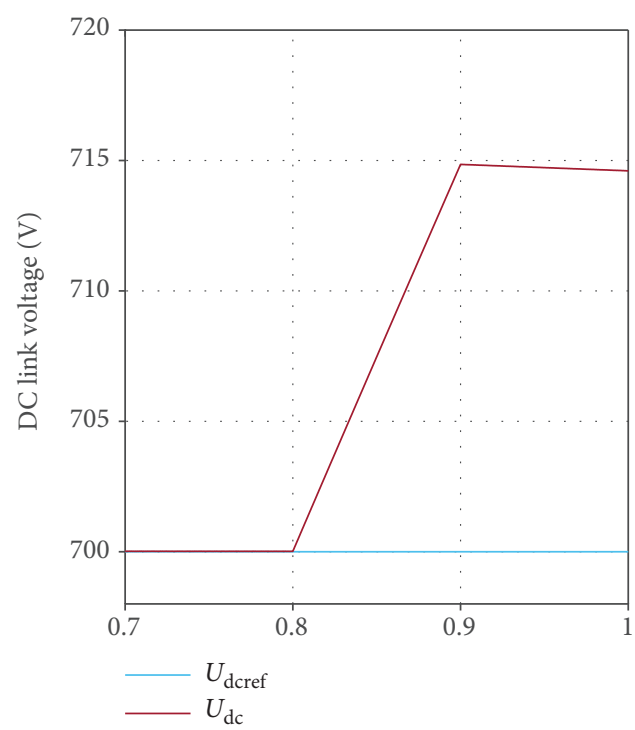

(a)

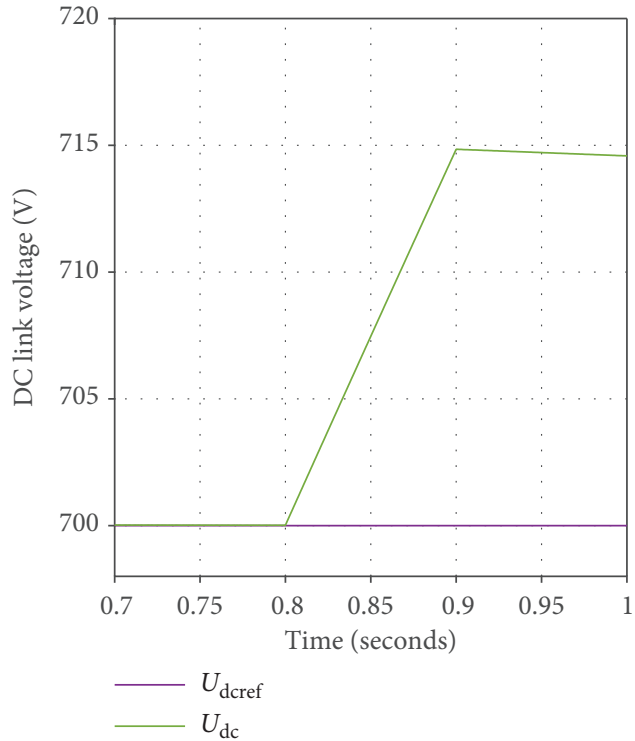

(c)

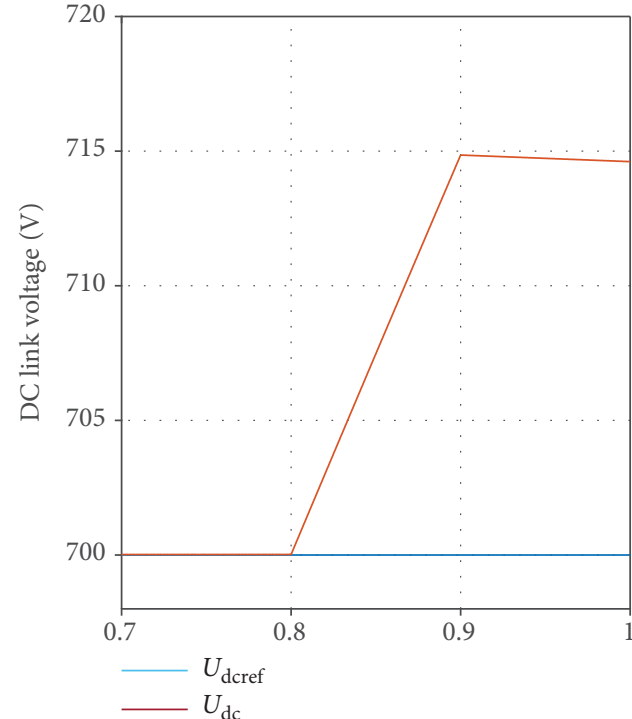

(b)

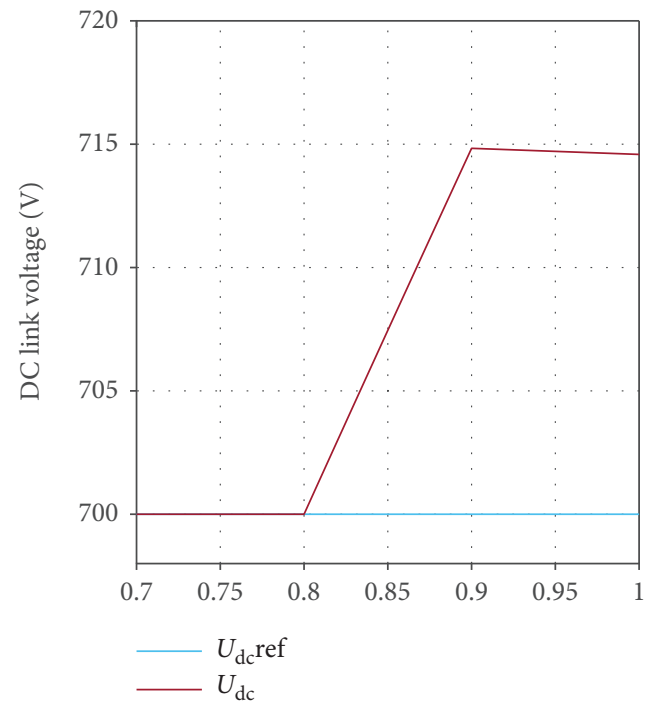

(d)

FIGURe 19: Voltage dip effect on DC link voltage with limitation by using (a) PSO-PID; (b) GA-FOPID; (c) ACO-PID; (d) TLBO-FOPID.

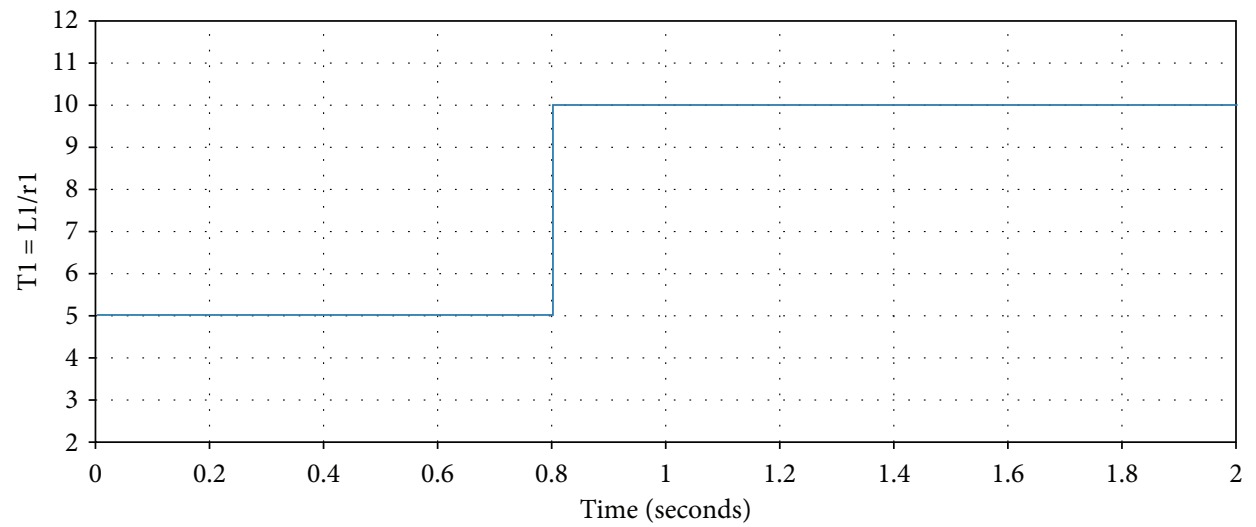

FIgUre 20: Time constant of the line. 


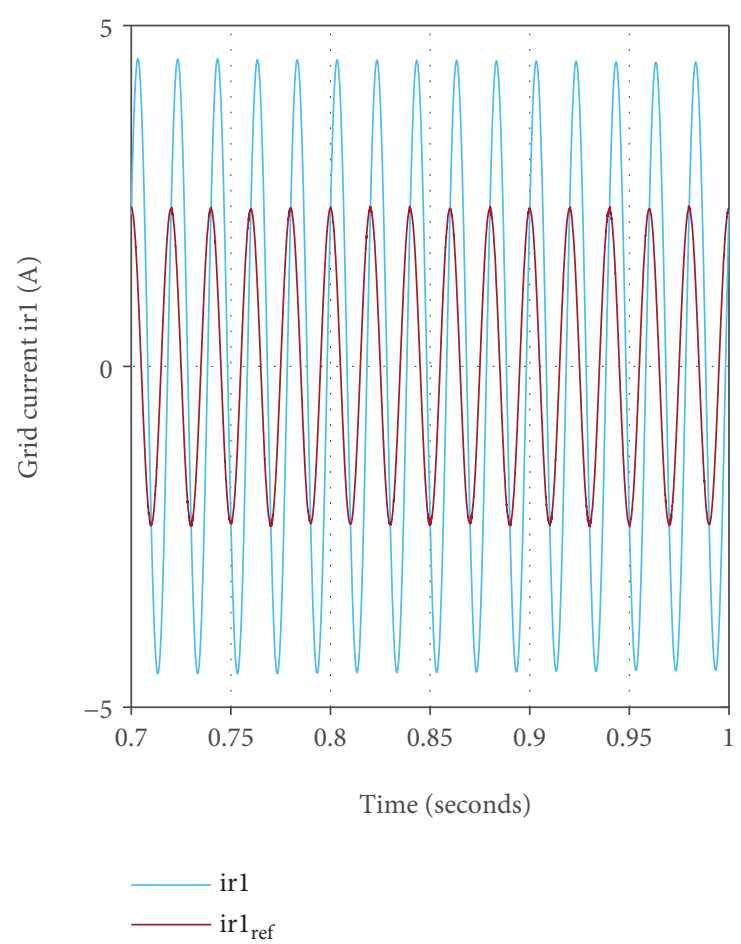

(a)

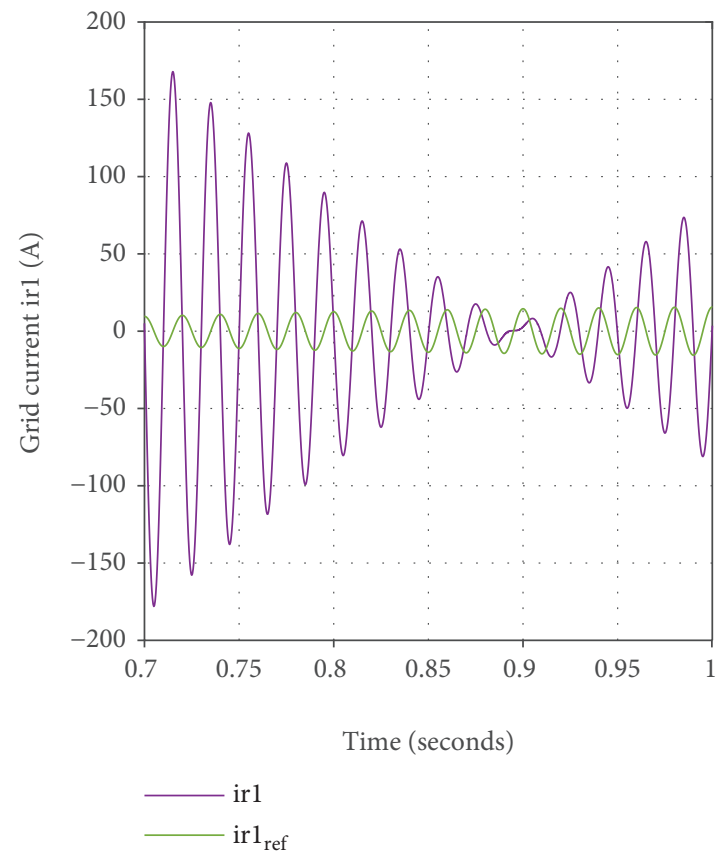

(c)

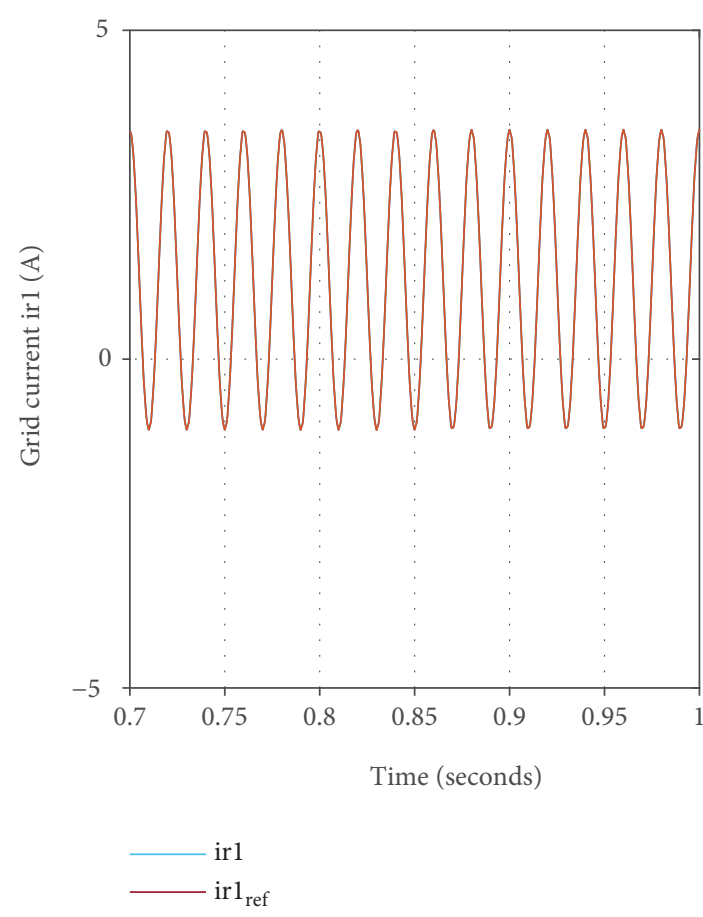

(b)

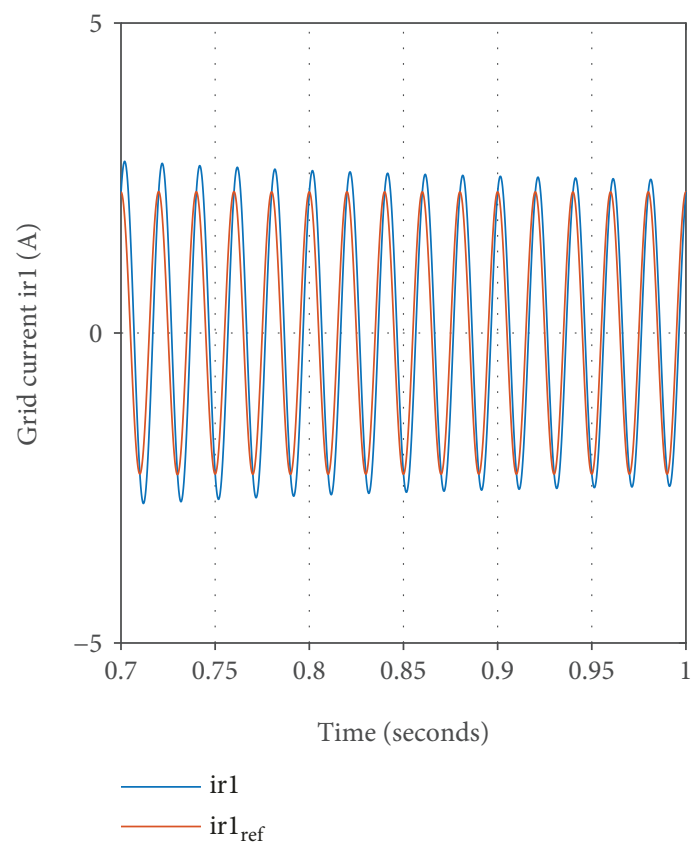

(d)

Figure 21: The effect of line resistance sudden decrease on the grid currents by using (a) PSO-PID; (b) TLBO-FOPID; (c) ACO-PID; (d) GA-FOPID.

Figure 17 validates the DC link voltage controller which is able to force the measured DC link voltage to track its reference when the system experiences a $50 \%$ voltage dip without limitation of the grid current amplitude at $t=[0.8 \mathrm{~s}$, $0.9 \mathrm{~s}$. This defect involves an increase in the grid currents as portrayed in Figure 15, whereas $U_{\mathrm{dc}}$ remains constant thanks to the MPPT algorithm. Results of the control strategies are approximately similar.

4.3. Control under Voltage Dips with Current Limitation. Similarly, Figures 18 and 19 highlight the impact of the same voltage dip of the grid on the DC link voltage and the grid 
currents with limitation of their amplitudes. This limitation provokes an increase in DC link voltage as illustrated in Figure 19. Results are close and the robustness of the control techniques is proven if such a defect occurs.

4.4. Control under Parametric Variation. A reduction of $50 \%$ of resistance $\mathbf{r}_{1}$ leads to an increase of $100 \%$ of the time constant $\left(\mathbf{T}_{1}=\mathbf{L}_{1} / \mathbf{r}_{1}\right)$ as shown in Figure 20 . The results of simulation given in Figure 21 prove the reliability of the cascade TLBO-FOPID control to sudden parametric variations of the system as compared to the other controllers. In fact, only the TLBO-FOPID controller shows ability to deliver the desired output power to the grid with a unity power factor; in other words, TLBO-FOPID keeps the output current in phase with the grid voltage. However, the ACOPID controller is unable to address this defect since the steady state has not been reached yet when the resistance value varies.

\section{Conclusion}

A comparative assessment between the proposed TLBOFOPID and three controllers is presented in this paper, namely, GA-FOPID, PSO-PID, and ACO-PID for a gridconnected PV system. For superior tracking efficiency, a $\mathrm{P} \& \mathrm{O}$-based MPPT algorithm is employed to extract the maximum power from PV panels. All of the control strategies are designed for controlling all cascade loops in the conversion chain in order to eliminate the grid current harmonics. Performances of the controllers are compared when fastchanging solar irradiation, voltage dip, and parametric variations of the system are experienced. The TLBO-FOPID addresses all the already quoted challenges. Simulations have been conducted using MATLAB/Simulink validating the functionality, robustness, and simplicity of the algorithm compared with the other metaheuristic techniques.

\section{Data Availability}

The data used to support the findings of this study are available from the corresponding author upon request.

\section{Conflicts of Interest}

The authors declare that there is no conflict of interest regarding the publication of this paper.

\section{References}

[1] E. Koutroulis and F. Blaabjerg, "Overview of maximum power point tracking techniques for photovoltaic energy production systems," Electric Power Components and Systems, vol. 43, no. 12, pp. 1329-1351, 2015.

[2] G. A. Raducu, Control of Grid Side Inverter in a B2B Configuration for WT Applications, Master, Aalborg University, 2008.

[3] J. Hu, J. Zhu, and D. G. Dorrell, "Model predictive control of grid-connected inverters for PV systems with flexible power regulation and switching frequency reduction," IEEE Transactions on Industry Applications, vol. 51, no. 1, pp. 587-594, 2015.
[4] H. Boumaaraf, A. Talha, and O. Bouhali, "A three-phase NPC grid-connected inverter for photovoltaic applications using neural network MPPT," Renewable and Sustainable Energy Reviews, vol. 49, pp. 1171-1179, 2015.

[5] M. Sreedevi and P. J. Paul, "Fuzzy PI controller based gridconnected PV system," International Journal of Soft Computing, vol. 6, no. 1, pp. 11-15, 2011.

[6] K. K. Tan, S. Huang, and R. Ferdous, "Robust self-tuning PID controller for nonlinear systems," Journal of Process Control, vol. 12, no. 7, pp. 753-761, 2002.

[7] D. Valério and J. S. da Costa, "Tuning of fractional PID controllers with Ziegler-Nichols-type rules," Signal Processing, vol. 86, no. 10, pp. 2771-2784, 2006.

[8] J. Kennedy and R. Eberhart, "Particle swarm optimization," in Proceedings of ICNN'95 - International Conference on Neural Networks, vol. 4, pp. 1942-1948, Perth, Australia, 1995.

[9] K. Tayal and V. Ravi, "Particle swarm optimization trained class association rule mining: application to phishing detection," in Proceedings of the International Conference on Informatics and Analytics - ICIA-16, vol. 8, pp. 1-13, Pondicherry, India, August 2016.

[10] K.-P. Wang, L. Huang, C.-G. Zhou, and W. Pang, "Particle swarm optimization for traveling salesman problem," in Proceedings of the 2003 International Conference on Machine Learning and Cybernetics (IEEE Cat. No.03EX693), pp. 15831585, Xi'an, China, 2003.

[11] A. Carlisle and G. Dozier, "Adapting particle swarm optimization to dynamic environments," in International Conference on Artificial Intelligence, pp. 429-434, 2000.

[12] U. Baumgartner, C. Magele, and W. Renhart, "Pareto optimality and particle swarm optimization," IEEE Transactions on Magnetics, vol. 40, no. 2, pp. 1172-1175, 2004.

[13] M. I. Solihin, L. F. Tack, and M. L. Kean, "Tuning of PID controller using particle swarm optimization (PSO)," International Journal on Advanced Science, Engineering and Information Technology, vol. 1, no. 4, pp. 458-461, 2011.

[14] I. Petráš, L. Dorčák, and I. Koštial, "Control quality enhancement by fractional order controllers," Acta Montanistica Slovaca, vol. 3, no. 2, pp. 143-148, 1998.

[15] C. Y. Monje, A. Concepción, and B. M. Vinagre, "Proposals for fractional PI $\lambda \mathrm{D} \mu$ tuning," in Proceedings of Fractional Differentiation and Its Applications, pp. 1-6, 2004.

[16] Y. Chen, T. Bhaskaran, and D. Xue, "Practical tuning rule development for fractional order proportional and integral controllers," Journal of Computational and Nonlinear Dynamics, vol. 3, no. 2, article 021403, 2008.

[17] D. E. Seborg, T. F. Edgar, and D. A. Mellichamp, Process Dynamics and Control, John Wiley \& Sons, New York, 2004.

[18] V. M. Alfaro, R. Vilanova, and O. Arrieta, "Robust tuning of twodegree-of-freedom (2-DoF) PI/PID based cascade control systems," Journal of Process Control, vol. 19, no. 10, pp. 16581670, 2009.

[19] I. Kaya, N. Tan, and D. P. Atherton, "Improved cascade control structure for enhanced performance," Journal of Process Control, vol. 17, no. 1, pp. 3-16, 2007.

[20] T. Liu, D. Gu, and W. Zhang, "Decoupling two-degree-of-freedom control strategy for cascade control systems," Journal of Process Control, vol. 15, no. 2, pp. 159-167, 2005.

[21] C. C. Hang, A. P. Loh, and V. U. Vasnani, "Relay feedback autotuning of cascade controllers," IEEE Transactions on Control Systems Technology, vol. 2, no. 1, pp. 42-45, 1994. 
[22] S. Vivek and M. Chidambaram, "Cascade controller tuning by relay auto tune method," Journal of the Indian Institute of Science, vol. 84, pp. 89-97, 2004.

[23] Y. Lee, S. Park, and M. Lee, "PID controller tuning to obtain desired closed loop responses for cascade control systems," Industrial \& Engineering Chemistry Research, vol. 37, no. 5, pp. 1859-1865, 1998.

[24] T. F. Edgar, R. Heeb, and J. O. Hougen, "Computer-aided process control system design using interactive graphics," Computers \& Chemical Engineering, vol. 5, no. 4, pp. 225-232, 1982.

[25] P. R. Krishnaswamy, G. P. Rangaiah, R. K. Jha, and P. B. Deshpande, "When to use cascade control," Industrial \& Engineering Chemistry Research, vol. 29, no. 10, pp. 21632166, 1990.

[26] M. V. Sadasivarao and M. Chidambaram, "PID controller tuning of cascade control systems using genetic algorithm," Journal of Indian Institute of Science, vol. 86, no. 7, pp. 343354, 2006.

[27] J. Grefenstette, "Optimization of control parameters for genetic algorithms," IEEE Transactions on Systems, Man, and Cybernetics, vol. 16, no. 1, pp. 122-128, 1986.

[28] R. Luus and T. H. I. Jaakola, "Optimization by direct search and systematic reduction of the size of search region," AICHE Journal, vol. 19, no. 4, pp. 760-766, 1973.

[29] W. Lhomme, P. Delarue, F. Giraud, B. Lemaire-Semail, and A. Bouscayrol, "Simulation of a photovoltaic conversion system using Energetic Macroscopic Representation," in 2012 15th International Power Electronics and Motion Control Conference (EPE/PEMC), Novi Sad, Serbia, September 2012.

[30] M. H. Boujmil, A. Badis, and M. Nejib Mansouri, "Nonlinear robust backstepping control for three-phase grid-connected PV systems," Mathematical Problems in Engineering, vol. 2018, Article ID 3824628, 13 pages, 2018.

[31] S. Das, I. Pan, S. Das, and A. Gupta, "Improved model reduction and tuning of fractional-order $P I^{\lambda} D^{\mu}$ controllers for analytical rule extraction with genetic programming," ISA Transactions, vol. 51, no. 2, pp. 237-261, 2012.

[32] R. V. Rao, V. J. Savsani, and D. P. Vakharia, "Teaching-learning-based optimization: a novel method for constrained mechanical design optimization problems," Computer Design, vol. 43, no. 3, pp. 303-315, 2011.

[33] P. Shah and S. Agashe, "Experimental analysis of fractional PID controller parameters on time domain specifications," Progress in Fractional Differentiation and Applications, vol. 3, no. 2, pp. 141-154, 2017. 

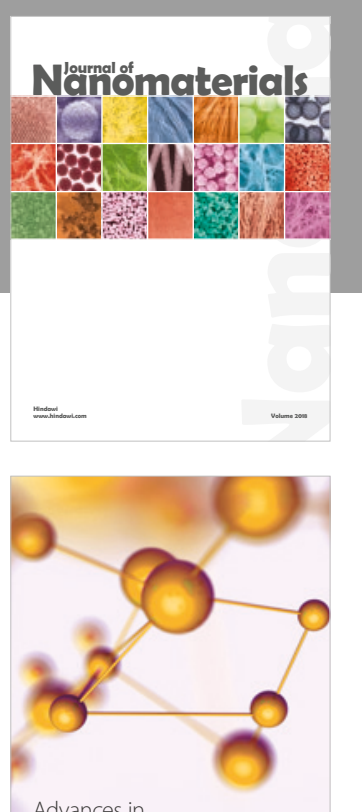

Physical Chemistry
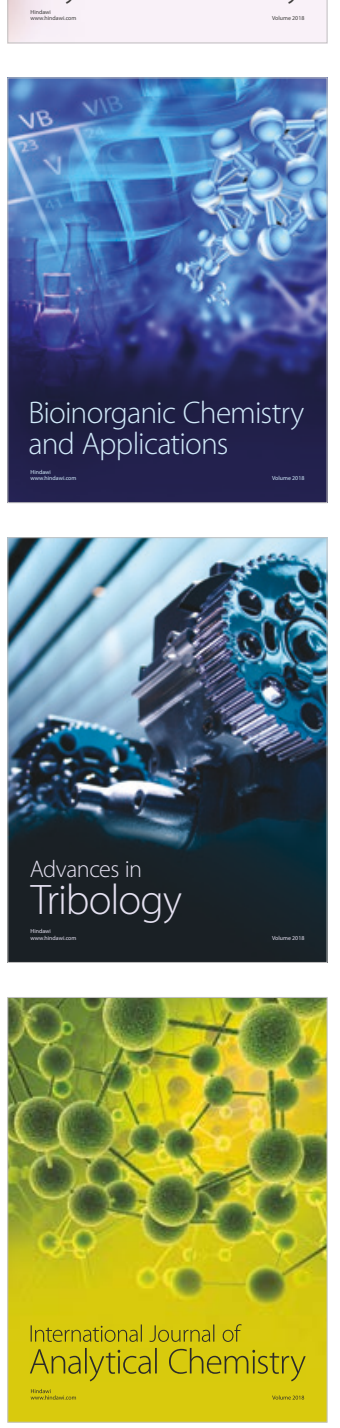

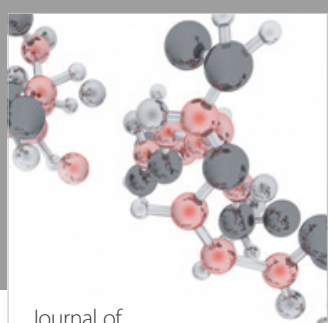

Analytical Methods

in Chemistry

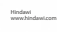

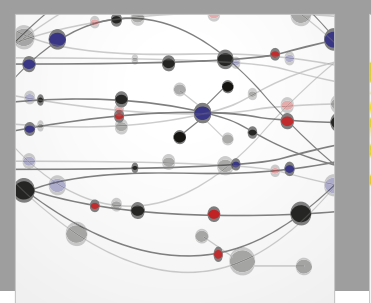

The Scientific World Journal

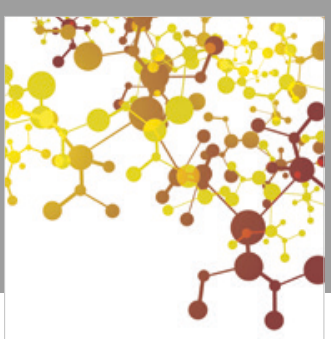

Journal of

Applied Chemistry
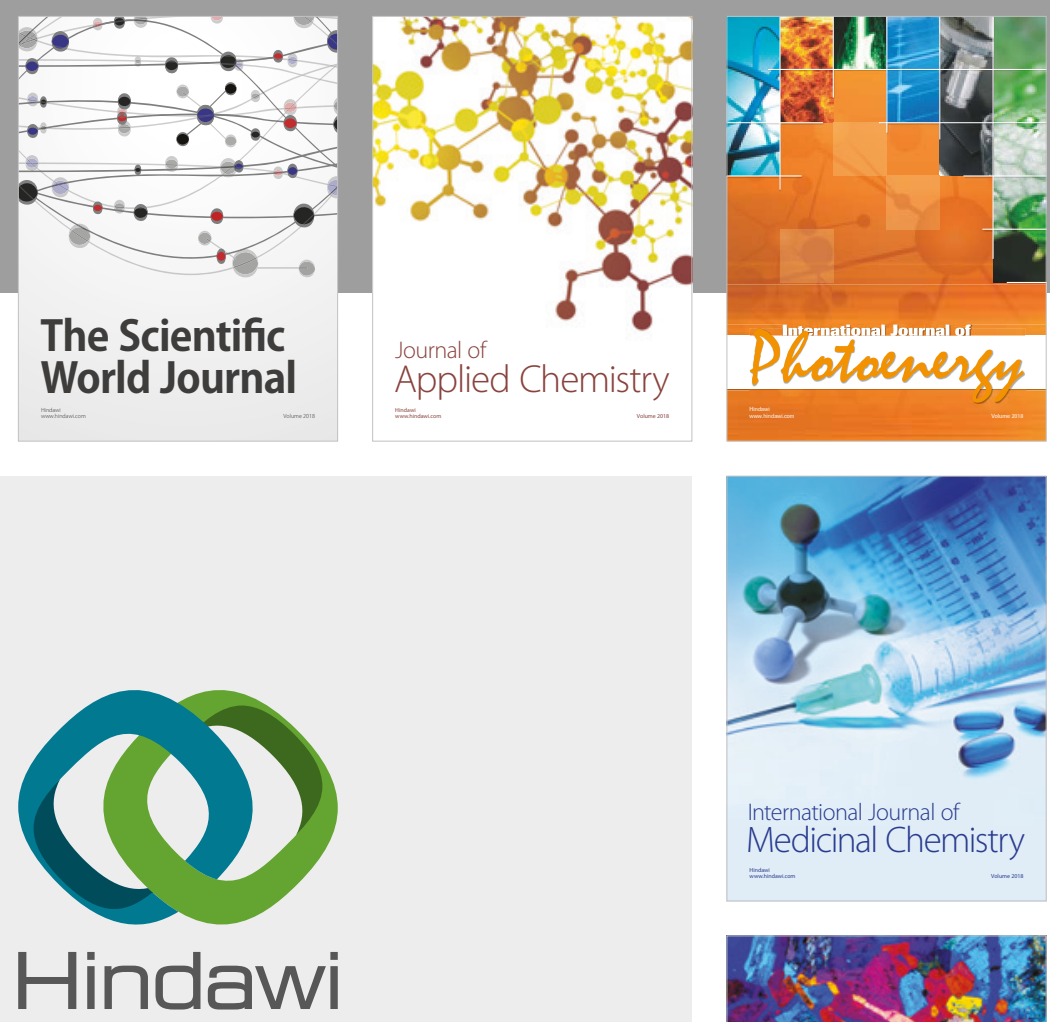

Submit your manuscripts at

www.hindawi.com
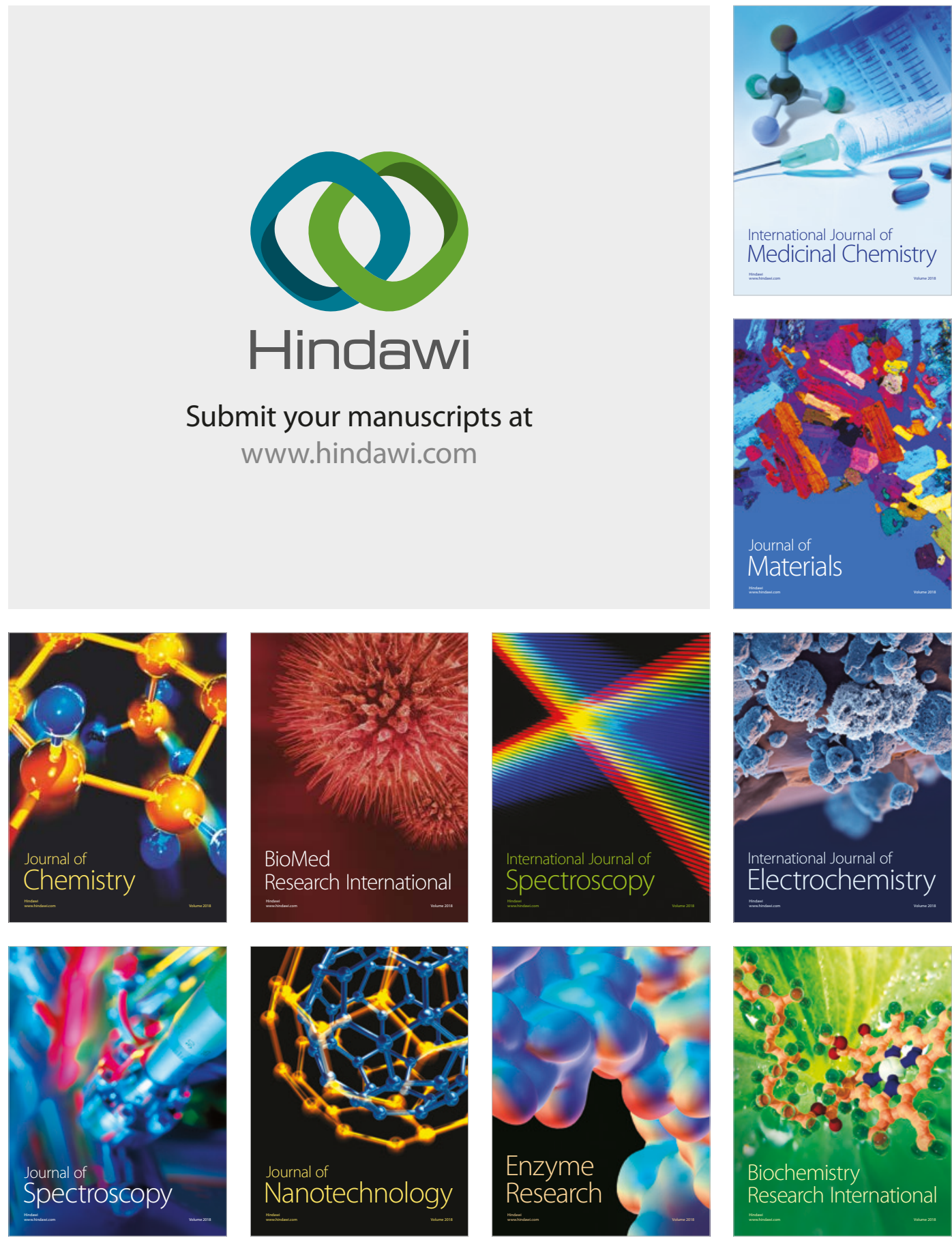
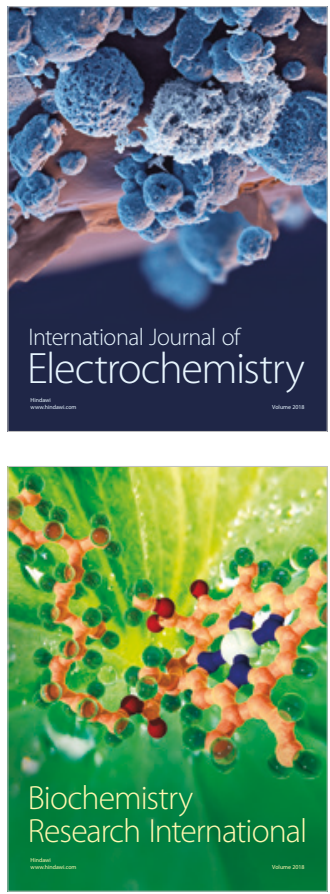